1 Detailed analysis of the ice surface after binding of

2 an insect antifreeze protein and correlation with the

\title{
Gibbs-Thomson equation
}

KIT (Karlsruhe Institute of Technology), Institute of Process Engineering in Life Sciences, Section I: Food Process Engineering, Kaiserstraße 12, 76131 Karlsruhe, Germany

10 ABSTRACT

11 Antifreeze proteins are able to influence the ice crystal growth and the recrystallization process

12 due to the Gibbs-Thomson effect. The binding of the antifreeze protein leads to the formation of a

13 curved ice surface and it is generally assumed that there is a critical radius between the proteins

14 on the ice surface that determines the maximal thermal hysteresis. Up to now, this critical radius

15 has not yet been proven beyond doubt or only in poor agreement with the Gibbs-Thomson 16 equation. Using molecular dynamics (MD) simulations, the resulting three-dimensional surface 
17 structure is analyzed and the location of the critical radius is identified. Our results demonstrate

18 that the correct analysis of the geometry of ice surface is extremely important and cannot be

19 guessed upfront the simulation. In contrary to earlier expectations from literature, we could show

20 that the critical radius is not located directly between the adsorbed proteins. In addition, we showed

21 that the minimum temperature at which the system does not freeze is in very good agreement with

22 the value calculated with Gibbs-Thomson equation at the critical radius as long as dynamic system

23 conditions are taken into account. This proves on the one hand that the Gibbs-Thomson effect is

24 the basis of thermal hysteresis and that MD simulations are suitable for the prediction of the

25 melting point depression.

26 INTRODUCTION

27 Several microorganisms, animals and plants inhabiting cold climates produce specialized 28 proteins called antifreeze proteins (AFP) or ice-binding proteins (IBP). These proteins protect body

29 fluids from cold damage ${ }^{1-4}$. Under subzero temperature conditions ice crystals can form in body

30 fluids like cytoplasm, blood or haemolymph, and in the apoplast of plants ${ }^{3}$. This leads to serious

31 damage within the surrounding tissue. In addition to physical damage, the formation of

32 intracellular ice results in an increase of osmotic pressure due to the removal of liquid water and

33 concentration of the remaining solutes ${ }^{5}$, which causes plasmolysis and disruption of the cell

34 integrity. For this reason, AFP are of special interest in industrial and medical applications for

35 example as food additive in frozen meat, fish or ice cream or as cryoprotective agent during frozen

36 storage of cells, tissues and organs ${ }^{6}$.

37 AFP bind to specific planes of ice crystals and thus inhibit further ice growth during cooling to

38 a certain extent. The resulting gap between the equilibrium melting temperature and the

39 temperature of sudden ice growth is called thermal hysteresis $(\mathrm{TH})^{7,8}$. Many authors term the 
40 temperature of sudden ice growth the "freezing point" which is physically not correct, as ice

41 crystals are already present when their growth is stopped by AFP. Moreover, bound AFPs are able

42 to increase the equilibrium melting temperature of the ice crystal but in a smaller extent compared

43 to $\mathrm{TH}^{9}$.

44 Different characteristics of antifreeze proteins influence their ability to stop ice crystal growth

45 and thereby the extent of the TH. One critical property is the ice plane bound by the AFP (Figure

46 1). Two types of AFP can be distinguished, moderately active and hyperactive AFP. Hyperactive

47 AFP are able to bind to the basal plane or to the basal in combination with other planes ${ }^{10,11}$ and are

48 found in insects and some microorganisms ${ }^{12}$. Their activity is up to ten fold higher than the one of

49 moderately active AFP, which are typically found in fish ${ }^{13}$. Moderately active AFP bind preferably

50 to planes parallel to the c axis ${ }^{8}$. For example, winter flounder AFP binds to the pyramidal plane ${ }^{14}$.

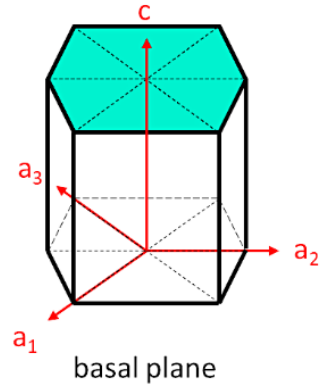

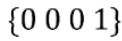

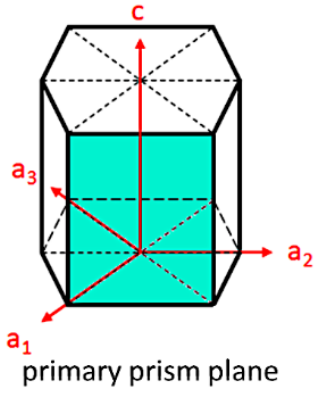

$\left\{\begin{array}{llll}1 & 0 & \overline{1} & 0\end{array}\right\}$

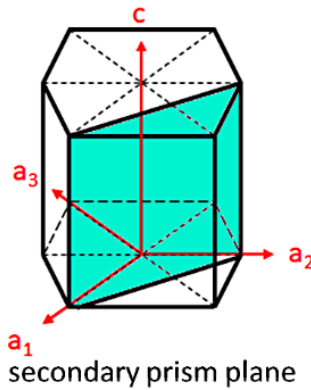

$\{11 \overline{2} 0\}$

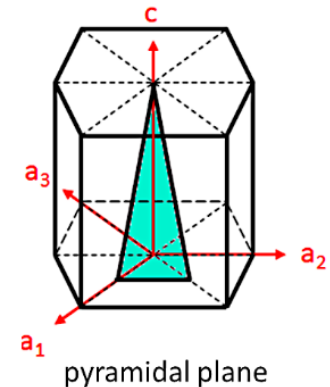

$\{20 \overline{2} 1\}$

52 Figure 1. Possible ice binding planes for AFP. The specific plane is shown in turquoise with the

53 corresponding miller index. Modified from ${ }^{13}$.

54 Besides being able to influence the freezing and melting behavior of an ice crystal, AFPs affect

55 the ice recrystallization. During the process of ice recrystallization, the total mass of ice crystals is

56 constant whilst the number of crystals decrease and the mean ice crystal sizes increase ${ }^{15,16}$ by

57 thermodynamic reasons. The addition of AFP reduces recrystallization effects even when they are

58 added in low concentrations ${ }^{17,18}$. 
59 In general, it is postulated that, due to their ability to interact with the ice crystal surface, the

60 presence of AFP leads to a pinned surface with characteristic curvature ${ }^{19}$ (Figure 2).

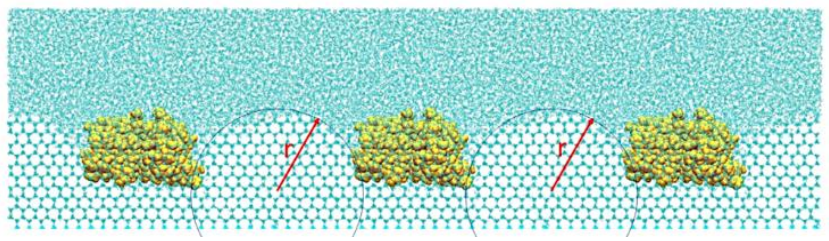

62 Figure 2. Curved ice surface between three antifreeze proteins (yellow). Ice can grow between the

63 proteins and forms a curved surface. The radius $r$ of the curvature influences the vapor pressure of

64 the solid phase, which leads to a limitation of the ice, although a decreasing temperature.

65 Both effects, TH and ice recrystallization inhibition, involve the Gibbs-Thomson effect ${ }^{20}$

66 (Equation 1), which describes the change of the melting temperature due to a curved surface at

67 constant pressure. A decisive parameter here is the radius $\mathrm{r}$ or the diameter $\mathrm{x}=2 \mathrm{r}$ of the curvature.

68 Equation 1. Gibbs-Thomson equation for a spherical particle

$$
\Delta T_{m}=T_{m}^{\infty}-T_{m}(x)=\frac{4 \sigma_{s l} T_{m}^{\infty}}{x \Delta H_{f} \rho_{s}}
$$

70 For the calculation of the thermal hysteresis $\Delta T_{m}$, which is the difference between the bulk

71 melting temperature $T_{m}^{\infty}$ and the melting temperature of the ice crystal $T_{m}(x)$ with a diameter of

72 size $\mathrm{x}$, the surface tension $\sigma_{s l}$ between the solid and liquid phase, the bulk enthalpy of fusion $\Delta H_{f}$

73 and the density of the solid $\rho_{s}$ is needed. The factor of four, often referred to as geometry factor,

74 originates from the Young-Laplace equation (Equation 2), which describes the pressure difference

$75 \Delta \mathrm{p}$ across a curved interface. 
Equation 2. Young-Laplace equation

$$
\Delta p=-\sigma\left(\frac{1}{r_{1}}+\frac{1}{r_{2}}\right)
$$

If a spherical particle or surface is assumed, both principal radii $r_{1}$ and $r_{2}$ are of the same length and can be combined to $2 / \mathrm{r}$ or $4 / \mathrm{x}$. This results in a geometrical factor of 4 as seen in Equation 1.

84 In the case of a cylindrical shape, one of the radii becomes infinite and therefore only the radius

85 perpendicular to the height of the cylinder has an influence. This results in $1 / \mathrm{r}$ or $2 / \mathrm{x}$, and leads to a geometric factor of two for a cylindrical shape in Equation 1. It is obvious that the value of $T_{m}(x)$

87 depends not only on the radius but also on the given geometry. Unfortunately, less attention is paid to the latter in the literature.

89 To prove the assumption that the Gibbs-Thomson Effect leads to TH of AFP many attempts 90 have been discussed in literature. As it is impossible by direct observation to proof the existence 91 of the curvature on an AFP studded ice crystal surface, to measure the curvatures or the surface

92 allocation of the bound molecules, most studies are based on simulation results from molecular 93 dynamics (MD) studies.

94 Experimentally, the binding plane or multiple binding planes can be identified with fluorescence 95 labeled $\mathrm{AFP}^{21,22}$ and the $\mathrm{TH}$ activity can be determined by differential scanning calorimetry, 96 sonocrystallization or other methods ${ }^{23-25}$. In addition, the ice recrystallization inhibition can be 97 quantified by several assays and optical methods ${ }^{18}$. An attempt to determine the surface 98 distribution of bound AFP molecules experimentally in an indirect way was described by Drori et $99 \mathrm{al}^{26}$. Fluorescence labeled Tenebrio molitor AFP (TmAFP) bind to a single ice crystal in a 100 specialized microfluidic system. Due to the intensity of the emitted light, the number of bound 101 molecules can be determined. From these investigations, Drori et al. calculated an average distance 102 of $7 \mathrm{~nm}$ for a measured $\mathrm{TH}$ value of $0.73 \mathrm{~K}$. 
103 In contrast to experimental methods, MD simulations can deliver information about the details

104 on a molecular level. During the last decade, MD simulations gained a lot of importance in the

105 field of antifreeze and ice binding molecules. It is shown that the simulation results support the

106 theory of a curved ice surface and the applicability of the Gibbs-Thomson effect ${ }^{27-29}$. A point that

107 one has to keep in mind for MD simulations of AFP is that the simulations provide only

108 information about the interaction of the AFP with one specific ice plane. Nevertheless, crystal

109 growth is a three-dimensional process and AFP have different affinities for the different planes,

110 which makes a direct comparison of $\mathrm{TH}$ between experiment and simulation unfeasible.

111 Furthermore, it is necessary to run the simulation long enough to allow rare events to happen.

112 These in turn can lead to overgrowth of the protein if the ice crystal surface has developed a

113 distinctive curvature. The time period of the experiment is of course much longer than of the 114 simulation.

115 A good example is provided by Naullage et al. ${ }^{30}$. They compared the experimental findings of 116 Drori et al. with a MD simulation of TmAFP with a distance of $7.4 \mathrm{~nm}$ between the centers of mass 117 of the molecules resulting in a TH of $9 \mathrm{~K}$ after $100 \mathrm{~ns}$ of simulation time ${ }^{30}$. According to the large 118 difference of TH of the experimental results Naullage et al. argued that the experimental distance 119 is determined by averaging and statistical distribution of antifreeze molecules and that it is likely 120 that there are also larger open spaces in between that lower the extent of TH in the experiment. In 121 addition, the observation time in the experiment is much longer than in the simulation allowing for 122 rare formation of ice bridges. Based on this and additional simulations, Naullage et al. suggest, 123 "that the longest distances in the distribution control the thermal hysteresis" (Naullage et al. 2018, 124 page 1716). This seems reasonable, because the ice radius between two bound AFP may increase 125 with a greater distance between the bound molecules and because of this, $T_{m}(x)$ rises. We go along 
126 with this argumentation and want to add that the three-dimensional aspects of ice growth and the

127 dynamic equilibrium on the surface must be taken into account, too. Especially when it comes to

128 the critical radius and the linkage of this radius to the Gibbs-Thomson.

129 Although there are publications that analyze and address these aspects but do not combine them

130 into a complex overall picture. Kuiper et al. simulated the binding of spruce budworm (sbw) AFP

131 to an growing ice crystal and finds that the binding of the protein to the ice surface is facilitated

132 by ordered water molecules ${ }^{28}$. Moreover, this ordering seems responsible for the ice plane

133 specificity. In addition, they calculate the radius according to the Gibbs-Thomson equation with

134 cylindrical geometry factor and create an overlay of the curvature and the circular segment

135 obtained. Unfortunately, it is not clear from their publication why the cylindrical geometry factor

136 is used and why the overlay is created at the location between the sbwAFP since no complete

137 analysis of the three-dimensional ice surface structure is shown.

138 Also Midya et al. ${ }^{31}$ calculated the expected length of the radius according the Gibbs-Thomson 139 equation and compared it with their simulations at different temperatures. However, it is not clear

140 what geometry factor is used and where and how they measured the radius. Furthermore, the 141 expected and calculated radii differ by at least $1.8 \mathrm{~nm}$ from each other. Additionally, there are 142 several other publications that show a curved ice surface but do not link the radius of curvature 143 with the Gibbs-Thomson equation $27,29,32$.

144 An interesting difference between the simulations of Kuiper et al. and Midya et al. is the overall 145 structure of the ice surface. While Midya et al. visualize a spherical or ellipsoidal curvature with 146 the center at the intersection of the diagonals, Kuiper et al. assumes a cylindrical surface. As shown 147 above the geometrical factor used in the Gibbs-Thomson equation is critical for the calculation of 148 TH. As many different radii of curvature can be formed during the process of ice growth, from our 
149 point of view, the critical location where ice starts to overgrow the AFP needs first to be identified.

150 Second, the surface geometry at this point needs to be evaluated to identify the correct Gibbs

151 Thomson Eq. for the calculation of TH. This illustrates the importance of knowing the structure of

152 the ice surface and where different radii can be located.

153 Another important aspect is the dynamic behavior of the ice surface close to the equilibrium.

154 Water molecules are able to join or desorb the ice lattice, which leads to a fluctuation of the surface 155 curvature and thus its radius making a static evaluation unfavorable ${ }^{28}$.

156 To accomplish these aspects in this study, radii in all directions inside the simulation box will

157 be analyzed (Figure 5 A)) to identify the critical radius, which is decisive for the overgrowing ice

158 front. Due to the rectangular arrangement of the AFP in the simulation (Figure $3 \mathrm{~B}$ )), we expect a 159 spherical elevation in the center similar to Midya et al. to arise. As stated by Naullage et al. the 160 longest distance should yield the critical radius, which is the diagonal direction between two AFP 161 in our simulation setup. To our knowledge, this is the first time that the diagonal is explicitly taken 162 in consideration and that radii in all directions within the systems are observed to identify the 163 critical radius. Moreover, the temperature $T_{\text {Min }}$ at which the system remains unfrozen is 164 determined by simulating different temperatures. The ice surface in the system at $T_{\text {Min }}$ is then 165 analyzed in static and dynamic way and $T_{m}(x)$ is calculated with the Gibbs-Thomson equation.

166 This should yield the observed $T_{\text {Min }}$, verifying that MD simulations can predict accurately the 167 melting point depression in accordance with the Gibbs-Thomson equation for a given geometry.

169 EXPERIMENTAL

170 Software and simulation parameters 
171 The MD simulations done with GROMACS ${ }^{33}$ version 2019.3 are visualized and analyzed using 172 the Visual Molecular Dynamics ${ }^{34}$ (VMD) viewer. In order to achieve realistic properties of ice and 173 the freezing process, the TIP4P/Ice water model ${ }^{35}$ in combination with the OPLS-AA ${ }^{36}$ force field

174 is used. This water model is based on the four-site TIP4P model but the parameters are adapted to 175 yield a better phase transition behavior. With a melting point of $269.8 \pm 0.1 \mathrm{~K}^{37}$ compared to 229 $176 \mathrm{~K}$ of $\mathrm{TIP} \mathrm{P}^{38}$ it is appropriate for the simulated system. To control the pressure inside the 177 simulation box during the production run to 1 bar, an anisotropic Parrinello-Rahman barostat with 178 a coupling constant of $2 \mathrm{fs}$ is applied. After energy minimization, the temperature is set to the 179 desired value using a V-rescale thermostat in the canonical ensemble. Subsequently, the pressure 180 in the isobaric-isothermal ensemble is controlled with a Berendsen barostat. All bonds including 181 hydrogen atoms are constraint with the $\operatorname{LINCS}^{39}$ algorithm enabling an integration time step of 2 182 fs during the production run.

183 Furthermore, periodic boundary conditions (PBC) are used during the simulation to eliminate 184 boundary effects and to create a defined geometry of regularly distributed AFP molecules. 185 Therefore, the unit cell, which is the simulated system, is duplicated in all three dimensions and 186 placed around the simulation box (Figure 3). In Figure $3 \mathrm{~A}$ ) the principle of PBC is exemplarily 187 shown in two dimensions for the yellow molecule. Due to the periodic boundary the yellow atom, 188 which leaves the simulation box at the right side, re-enters from the left. 

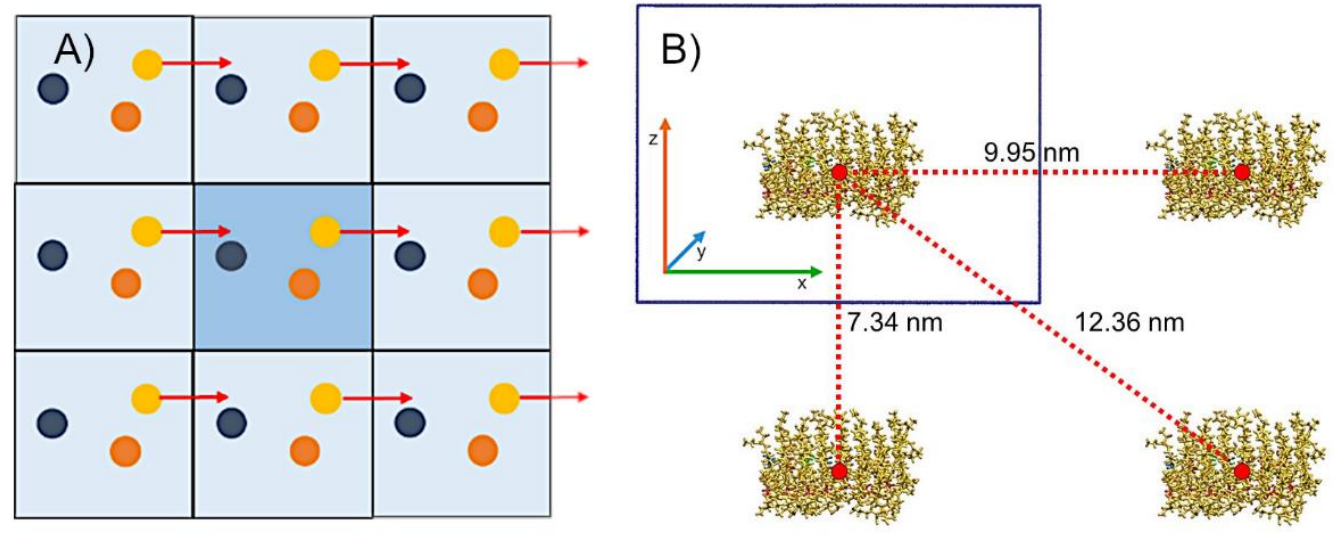

193 Figure 3. A) Simplified, two dimensional drawing of periodic boundary conditions in MD

194 simulations. The original simulation box is shown in darker blue in the center and contains three

195 example atoms (yellow, orange and dark blue). The simulation box is duplicated and placed around 196 the original simulation box, depicted in light blue. Due to the periodic boundary an atom that leaves

197 the box (yellow at the right side), re-enters from the other side (left). In our case, leaving and 198 entering "atoms" are water molecules. B) Geometry created by connecting four simulation boxes 199 with one adsorbed sbwAFP in each box. The size of the original simulation-box is shown by the 200 blue box. Logically, the distance between the centers of mass of the proteins (red dotted lines) is 201 equal to the corresponding box length in $\mathrm{x}$ - and z-direction respectively. The longest distance 202 between AFP in this arrangement is the diagonal with $12.36 \mathrm{~nm}$.

\section{Simulation system}

204 The simulation box with a size of $9.95 \mathrm{~nm} \times 9.98 \mathrm{~nm}$ x $7.35 \mathrm{~nm}$ in $\mathrm{x}-, \mathrm{y}$ - and $\mathrm{z}$-direction contains 20593560 atoms in total, whereof 1760 water molecules are restraint as a single ice layer (Figure 4 206 A)). Since it is highly unlikely that water will start crystallizing under the simulation conditions, 207 this ice layer functions as a seed crystal to promote ice crystal growth. To ensure binding of the 208 insect AFP, the ice layer is able to grow freely in direction of the secondary prism plane and the 209 AFP is oriented with its ice-binding site towards the ice front. A slab of 919 restraint water 
210 molecules prevents the growth of ice to the lower direction, which has to be avoided since three-

211 dimensional periodic boundary conditions are applied. The simulated sbwAFP (Figure 4 B))

212 (RCSB: $1 \mathrm{M} 8 \mathrm{~N}$ ) is a hyperactive insect AFP which is able to bind to the secondary prism plane and

213 the basal plane ${ }^{22,40}$. Kuiper et al. already demonstrated that this specific AFP is able to bind to the 214 secondary prism plane of a growing ice crystal in a MD simulation ${ }^{28}$.

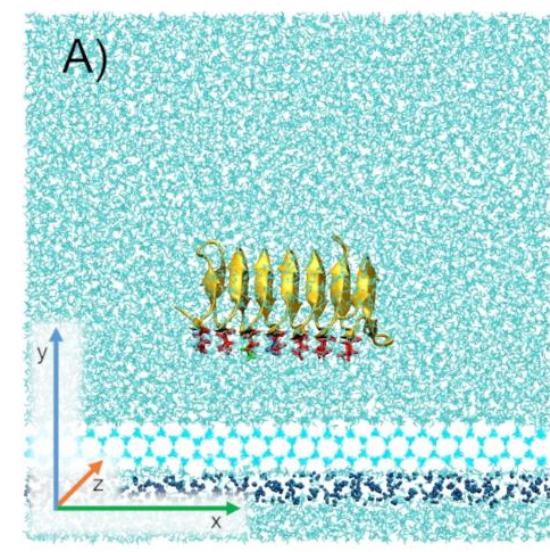

B)

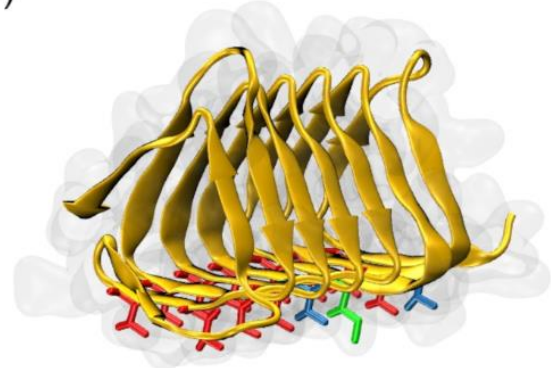

216 Figure 4. A) Starting configuration of the system. The spruce budworm AFP is placed in the center

217 and the ice-binding site is oriented towards the fixed ice layer (light blue). In addition, a fixed layer

218 of water molecules (blue dots) is introduced to prevent ice growth in the down direction. Finally,

219 the box is filled with water molecules (turquoise). B) Spruce budworm AFP visualized as a cartoon

220 drawing (yellow). For a better representation of the ice-binding site, the corresponding amino acids

221 are shown as licorice representation and in different colors. Threonine residues are depicted in red,

222 valine in blue and isoleucine in green. To get an impression of the dimension, the surface is

223 indicated as grey shadow.

224 Determination of $\boldsymbol{T}_{\text {Min }}$ after binding of sbwAFP

225 The temperature $T_{\text {Min }}$ is defined here as the lowest temperature at which the system does not 226 freeze completely. To determine $T_{\text {Min }}$, the box is simulated at different temperatures below the 
227 melting point and the state of the system is observed. In addition to the visual assessment if the

228 system is freezing or not, the progression of the density is examined to see density changes due to

229 the ice growing. Moreover, the simulation with the lowest temperature, which remains in a liquid

230 state, was repeated three times in total and extended to $300 \mathrm{~ns}$. The results are shown in Table 2.

231 These simulations will be abbreviated in the further course of this paper as Sim 1, Sim 2 and Sim

2323.

233

234 Visualization of the ice surface and determination of the curvatures radius

235 For the visualization of the ice surface and for the examination of the radius of curvature of the

236 ice crystal in between the bound molecules slabs are cut out the simulation box in several

237 directions. The advantage of using slabs is that the desired plane is visualized without

238 superimposition of water molecules in the planes behind and in front. An easy and fast method to

239 create those slabs is the use of the clipping plane tool in VMD. This tool allows cutting the three-

240 dimensional box along a plane which is defined by its vector and slabs with a thickness of $0.7-1$

$241 \mathrm{~nm}$ are created. Hence, the cuts can be set freely within the simulation box, it is possible to obtain

242 horizontal (xz plane) and vertical (yz plane) slabs. The horizontal slabs provide an overview of the

243 ice surface and allow the identification of the geometry of the ice surface landscape. To visualize

244 the curvature of the ice surface the vertical slabs are used. All vertical slabs, which are analyzed, 245 are shown in Figure 5 A) and alphabetically numbered. In order to calculate the radius based on 246 the vertical slabs, the chord length $\mathrm{s}$ and the height of a circular segment $\mathrm{h}$ (Equation 3, Figure 5 247 B)) are used. 

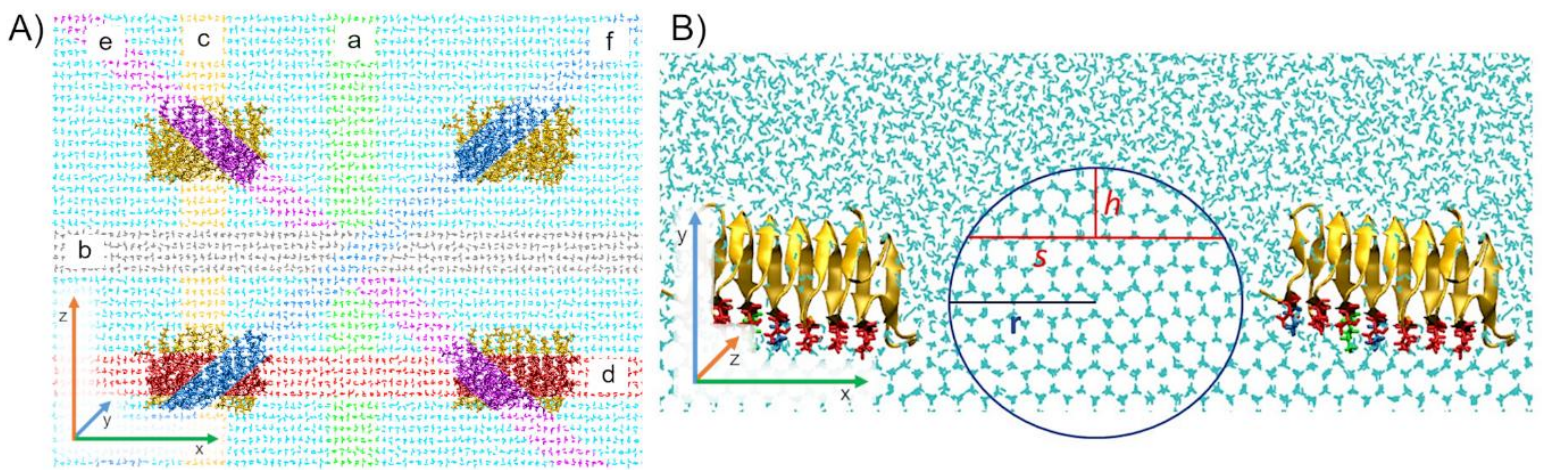

249 Figure 5. A) Slabs that are generated and observed during the simulation. The slab of the xz plane

250 is shown from the top. B) Exemplary image of slab d (xy plane) viewed from the front of the box.

251 The radius $r$ can be obtained by measuring the length $\mathrm{s}$ of the chord and the corresponding height

252 h.

253 Equation 3. Calculation of the radius of a circular segment

$$
r=\frac{4 h^{2}+s^{2}}{8 h}
$$

The precision of this method is estimated by calculating the radius three times at different heights

256 and chord lengths. Those radii result in three melting temperatures $T_{m}(x)$ according to the Gibbs-

257 Thomson equation. The greatest deviations occur when a clear phase boundary cannot be

258 identified. Taking this into account, the largest measured standard deviation is $0.574 \mathrm{~K}$ of 96 slabs

259 in total. To get a better overview over the deviation of this method, the smallest deviation and the

260 third quartile are determined which states that $75 \%$ of all deviations are less than or equal to this

261 value. They are $0.007 \mathrm{~K}$ and $0.234 \mathrm{~K}$, respectively. Moreover, the deviation of the individual

262 temperature ranges is far greater than the standard deviation caused by the determination method.

263 In conclusion, we can state that the performed determination method is a simple and quick analysis

264 with adequate accuracy. An alternative would be the calculation and usage of an order parameter

265 to create an artificial cutoff for the separation between ice and water. However, the selection of 
266 the cutoff value itself can influence the structure of ice surface, especially since it is a highly

267 dynamic interface and the computational time increases drastically for the analysis.

268 Depending on the ice surface geometry, the Gibbs-Thomson equation is adapted resulting in

269 Equation 4 for a cylindrical and Equation 5 for an arbitrary elliptical geometry. Subsequently, the

270 mean value and the corresponding standard deviation are calculated. When using two different

271 radii in the Gibbs-Thomson equation (Equation 5), the average value of the radii is used.

272 The radii depend on the dynamic and the geometry of the ice surface. Since the simulation at

$273 T_{\text {Min }}$ is repeated three times, a static evaluation at fixed times is performed to analyze differences

274 between identical starting setups. In addition to the static analysis, a dynamic analysis of the radii

275 is carried out. Here, the radii are measured over the course of the simulation whenever the

276 curvature is at its maximum.

277

278 Calculation of the expected TH with the Gibbs-Thomson equation

279 With the calculated radii of curvature, the expected depression of the melting temperature $T_{m}(x)$

280 is calculated with the Gibbs-Thomson equation (Equation 1). The parameters used are shown in

281 Table 1. They depend on the used water model and are specific for the pyramidal plane bound by

282 the AFP in the simulation. Depending on the geometry of the ice surface, the geometry factor of

283 the Gibbs-Thomson equation is adapted. The depressed melting temperature $T_{m}(x)$ of a cylindrical

284 surface with radius $r$ can be calculated according to Equation 4. 
Table 1. TIP4P/Ice parameters

\begin{tabular}{|l|l|}
\hline Property & Value \\
\hline Bulk melting temperature $T_{m}^{\infty} 37$ & $269.8 \mathrm{~K}$ \\
\hline Surface tension of the secondary prism plane $\sigma^{41}$ & $0.0316 \frac{\mathrm{J}}{\mathrm{m}^{2}}$ \\
\hline Enthalpy of fusion $\Delta H_{f} 41$ & $1.29 \frac{\mathrm{kcal}}{\mathrm{mol}}$ or $5397.36 \frac{\mathrm{J}}{\mathrm{mol}}$ \\
\hline Density of TIP4P/Ice ice ${ }^{37}$ & $906 \frac{\mathrm{kg}}{\mathrm{m}^{3}}$ \\
\hline Molecular weight of water and ice $M$ & $0.018 \frac{\mathrm{kg}}{\mathrm{mol}}$ \\
\hline
\end{tabular}

291 Equation 4. Gibbs-Thomson equation for a cylindrical surface geometry

$$
T_{m}(x)=T_{m}^{\infty}-\frac{M * \sigma * T_{m}^{\infty}}{\rho * \Delta H_{f} * r}
$$

Whereas $T_{m}(x)$ of an arbitrary elliptical geometry can be calculated with Equation 5 . This applies also for a spherical structure since this is a special case of an ellipse where both radii are 295 of the same length.

Equation 5. Gibbs-Thomson equation for an elliptical surface geometry with principal radii $\mathrm{r}_{1}$ and

$$
T_{m}(x)=T_{m}^{\infty}-\frac{M * \sigma * T_{m}^{\infty}}{\rho * \Delta H_{f}} *\left(\frac{1}{r_{1}}+\frac{1}{r_{2}}\right)
$$

Since many different slabs were evaluated, the ice crystal surface is analyzed in detail and the

300 critical radius determining the extent of the melting point depression can be identified. 


\section{Determination of $T_{M i n}$ after binding of sbwAFP}

308 For the determination of $T_{\min }$ different temperatures were simulated for at least $200 \mathrm{~ns}$. The

309 simulation results were analyzed at first visually and the state of the system was observed.

310 Secondly, a detailed analysis of the density curve was carried out.

311 The starting configuration is identical for each simulation (Figure $6 \mathrm{~A})$ ), the protein is oriented

312 with its ice-binding site towards the ice surface and is able to move freely within the box. At the

313 beginning, the ice grows in the y-direction and the distance to the protein becomes smaller. During

314 the first $50 \mathrm{~ns}$, the protein is able to bind to the growing ice crystal. Directly after the binding

315 process, no curvature is visible (Figure 6 B)). Remarkably, the protein binds in each of the eight

316 simulations performed but the binding orientation is slightly different which may influence the ice

317 formation. In some cases, the protein binds parallel to the x-axis and in other cases it is shifted.

318 This can exemplarily be seen in Figure 6 B) and D) where the proteins are shifted on one side in

319 the direction of the y-axis. In contrast, in Figure 6 C) it is bound to the ice surface parallel to the

$320 \mathrm{x}$-axis. An important aspect regarding the binding behavior is the interaction strength between the

321 protein and the ice surface. "AFPs that adsorb strongly will have higher surface concentrations and

322 a larger thermal hysteresis gap" (Kumari et al. 2020, page 2444) ${ }^{42}$. The simulative determination

323 of this interaction strength proves to be difficult, since the dynamic of the ice surface has a non-

324 negligible influence on the adsorption of the protein. This in turn depends on the force field and

325 the water model used. Therefore, a comparison and an estimation of which combination of force

326 field and water model provides the most accurate results or whether the influence of the force

327 fields is not decisive at all should be included in future studies . 
After the protein has bound to the ice surface, the ice crystal continues to grow and a curvature

329 is formed. With increasing curvature the radius and thus the melting temperature decreases and the

330 growing ice front is stopped if the set simulation temperature equals with the melting temperature

331 (Figure 6 C)). If the simulation temperature is lower and larger radii of curvature can be formed,

332 the AFP is overgrown and trapped inside the ice crystal (Figure 6 D)).
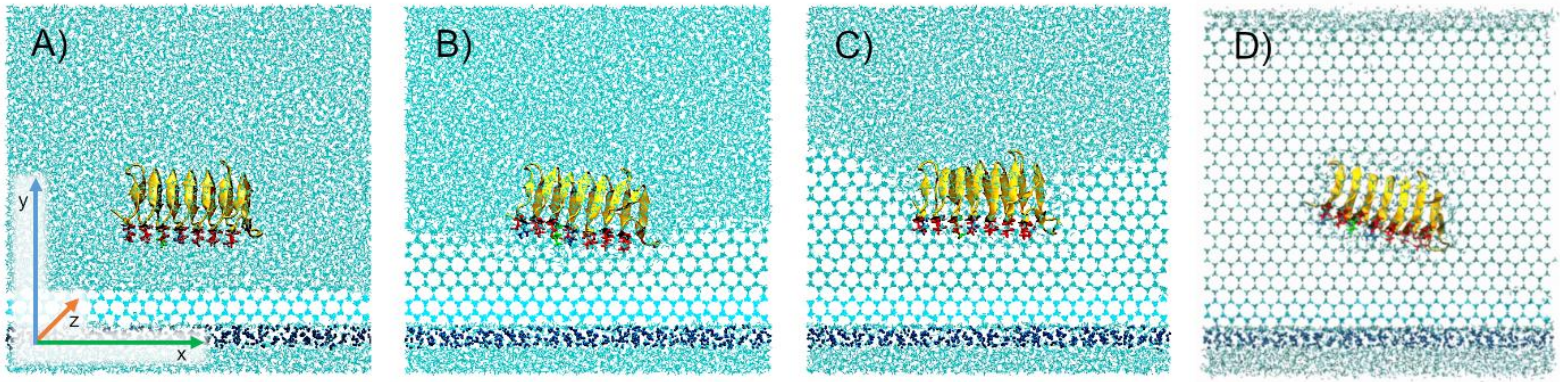

334 Figure 6. Basic course of the simulation and possible system states. A) Starting configuration,

335 which is the same for all simulations. B) The AFP is able to bind to the growing ice surface. The 336 picture is taken at a temperature of $262.5 \mathrm{~K}$ (Sim 3). C) After the binding process, ice continues to

337 grow and a curvature is formed. $(262.5 \mathrm{~K}$, Sim 1). D) If the temperature is too low, the protein is 338 overgrown and trapped in the ice $(262.2 \mathrm{~K})$. Depending on the actual degree of super cooling the 339 endpoint of the simulation is either C) or D).

340 According to the visual analysis of the simulation box, the temperature at which the system does 341 not freeze completely is at $262.5 \mathrm{~K}$ (Table 2). 
347 Table 2. System state after visual observation at different simulation temperatures

\begin{tabular}{|l|l|}
\hline Temperature / K & System state \\
\hline 260 & Frozen \\
\hline 261.5 & Frozen \\
\hline 262.0 & Frozen \\
\hline 262.2 & Frozen \\
\hline 262.5 & Unfrozen \\
\hline 265 & Unfrozen \\
\hline
\end{tabular}

349 Besides the visual observation, the density and the height of the ice layers were examined to 350 identify whether the system at the given temperature freezes or not. The development of the density 351 with and without AFP is shown in Figure 7. We assume that the ice growth rate is proportional to 352 the decrease of density. Without AFP, the system freezes within 100 ns at a temperature of $265 \mathrm{~K}$. 353 Due to the inserted ice grid, the density at the start of the simulation is already somewhat lower 354 than for pure water. In the further course of the simulation, the density decreases almost linearly 355 until the box is frozen in the y-direction. In case no AFP is present, a lowest density of $925 \mathrm{~kg} / \mathrm{m}^{3}$ 356 is reached (Figure $7 \mathrm{~A})$ ). In contrast, the presence of sbwAFP increases this value to about 935 $357 \mathrm{~kg} / \mathrm{m}^{3}$, assuming that the temperature is low enough for the ice to overgrow the protein (Figure 7 358 B)). Three phases can be identified that always occur in our simulations when the system with 359 AFP freezes completely. Figure 7 B) shows the density progression of a system at $262.2 \mathrm{~K}$ that 360 freezes in the course of the simulation. The three phases are alphabetically numbered from a to $\mathrm{c}$. 361 During phase a, the density decreases linearly due to the ice formation. After binding of the protein, 362 ice growth is impaired and the ice cannot longer grow with a straight surface. The pinning of the 363 ice surface results in a curvature and a reduced ice formation velocity (phase b). This means that 
364 the ice still continues to grow with a curved surface. As long as this curvature is not strong enough 365 to stop the ice growth, the ice is able to grow over the protein and a continuous layer can form. In

366 this case, the growth rate of the ice can increase again as can be seen in phase $\mathrm{c}$. The system then 367 freezes up to a density value of approximately $930 \mathrm{~kg} / \mathrm{m}^{3}$. This relation holds true for all 368 simulations below $262.5 \mathrm{~K}$.
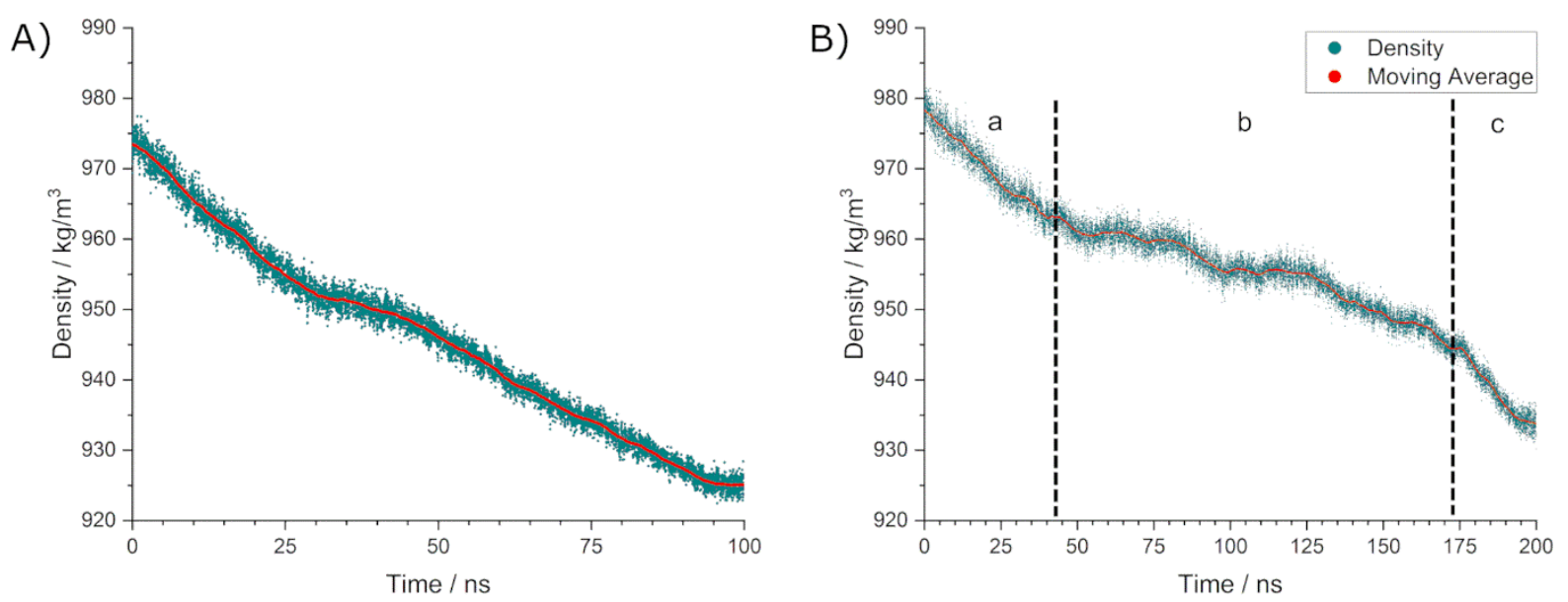

370 Figure 7. A) Progression of the density at $265 \mathrm{~K}$ without AFP. At the beginning, the density is

371 around $975 \mathrm{~kg} / \mathrm{m}^{3}$ and decreases linearly during the simulation. At $95 \mathrm{~ns}$ the box is frozen and the

372 density reaches a threshold of $925 \mathrm{~kg} / \mathrm{m}^{3}$. B) System with AFP at a temperature of $262.2 \mathrm{~K}$. The

373 density progression can be divided into three phases a-c. In the first phase (a) from 0 to 45 ns the

374 ice crystal grows and the protein binds to the ice surface. Afterwards, in the second phase (b), the

375 curvature develops but cannot stop the formation of ice. The velocity of the ice formation is

376 reduced. When the protein is engulfed and the first ice layer above the protein is formed, the

377 hindrance of ice formation is lower and thus the ice formation rate increases again. This can be 378 seen in the third phase (c).

379 At moderate supercooling, the resulting curvature prevents freezing and the course of the density 380 approaches a threshold value. The threshold value depends on temperature, since at higher 
381 temperatures the critical radius of curvature is larger and is therefore reached earlier. This limits

382 the maximum amount of ice in the system. For example, at a temperature of $262.5 \mathrm{~K}$ a lowest

383 density of approx. $960 \mathrm{~kg} / \mathrm{m}^{3}$ is reached (Figure 8), whereas at $265 \mathrm{~K}$ the density does not decrease 384 below $970 \mathrm{~kg} / \mathrm{m}^{3}$.

385 The simulation at $262.5 \mathrm{~K}$ was repeated three times in total. Hereinafter referred to as Sim 1 , 386 Sim 2 and Sim 3. This was done to see differences between individual simulations at the same 387 temperature, to evaluate the impact on the resulting curvature and to make sure that $262.5 \mathrm{~K}$ is the 388 critical temperature $T_{\min }$. Figure 8 shows the progression of the density of the three simulations at $389262.5 \mathrm{~K}$. Although all simulations have the same initial conditions, the ice formation and therefore 390 the density progression is not identical. One influence that may play a role here is the previously 391 mentioned slightly different binding configuration of the protein. For Sim 1 and Sim 2 the course 392 of the density is quite similar. It reaches apparently a constant value around $150 \mathrm{~ns}$ but afterwards 393 it decreases again. Even though a longer simulation might have led to an overgrowth of the protein, 394 this could not be observed in the simulations presented here. In contrast, Sim 3 approaches the 395 threshold slightly above $960 \mathrm{~kg} / \mathrm{m}^{3}$ and stays constant for the rest of the $450 \mathrm{~ns}$ of the simulation.

396 To ensure that the density reached a constant value, the simulation was extended from $300 \mathrm{~ns}$ to $397450 \mathrm{~ns}$. The initial ice formation seems to be the same for all three simulations, since the density 398 converges to a value of $960 \mathrm{~kg} / \mathrm{m}^{3}$ during the first $150 \mathrm{~ns}$. In this context, the simulation time 399 needed to produce reliable information is important. As seen in the density progressions of Sim 1 400 and Sim 2, the system would have been stable at around $150 \mathrm{~ns}$ without further simulation. This 401 may lead to wrong assumptions when systems with antifreeze molecules are simulated in a too 402 short range. This shows the principal need of relatively long simulation times for well-founded 403 statements. 

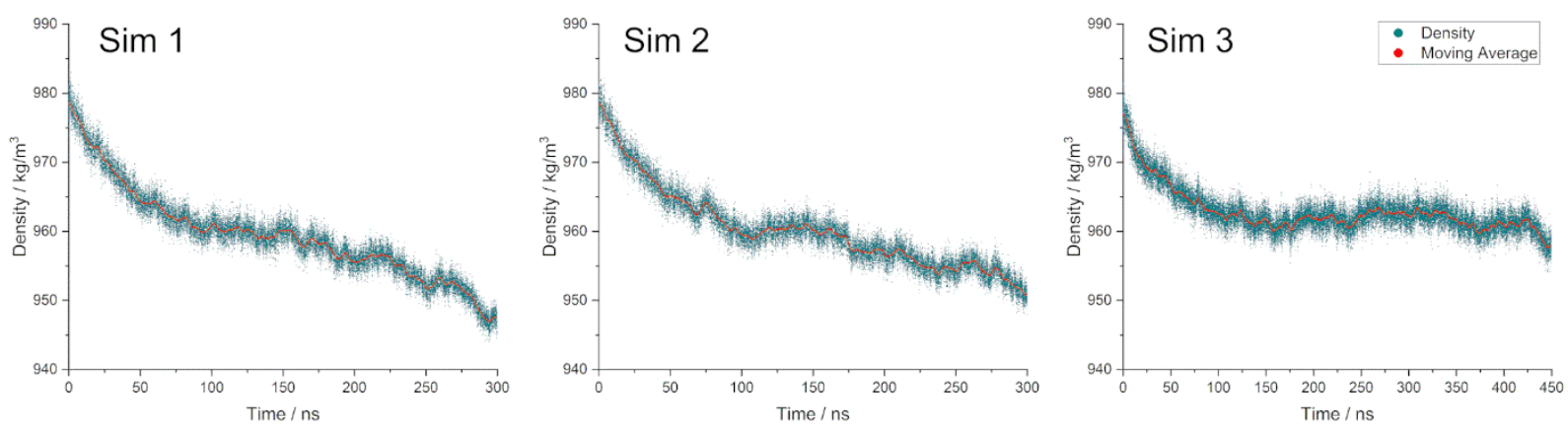

404

405

406

407

408

409

410

411 freeze for longer simulation times; the temperature $T_{\min }$ may be slightly higher. These three

412 simulations are analyzed in more detail below for the surface geometry and the different radii.

\section{$414 \quad$ Pre-analysis of the three dimensional ice surface at $\boldsymbol{T}_{\min }$}

415 Before the critical radius can be determined, the general structure of the ice surface needs to be 416 examined. A good way to get an overview over the geometry of the ice surface is to analyze

417 horizontal (xz plane) slabs through the simulation box (Figure 9). Because of its regular structure, 418 ice can easily be distinguished from the disordered water molecules. All three simulations at 262.5 419 K show the same cylindrical ice pattern at the surface. 


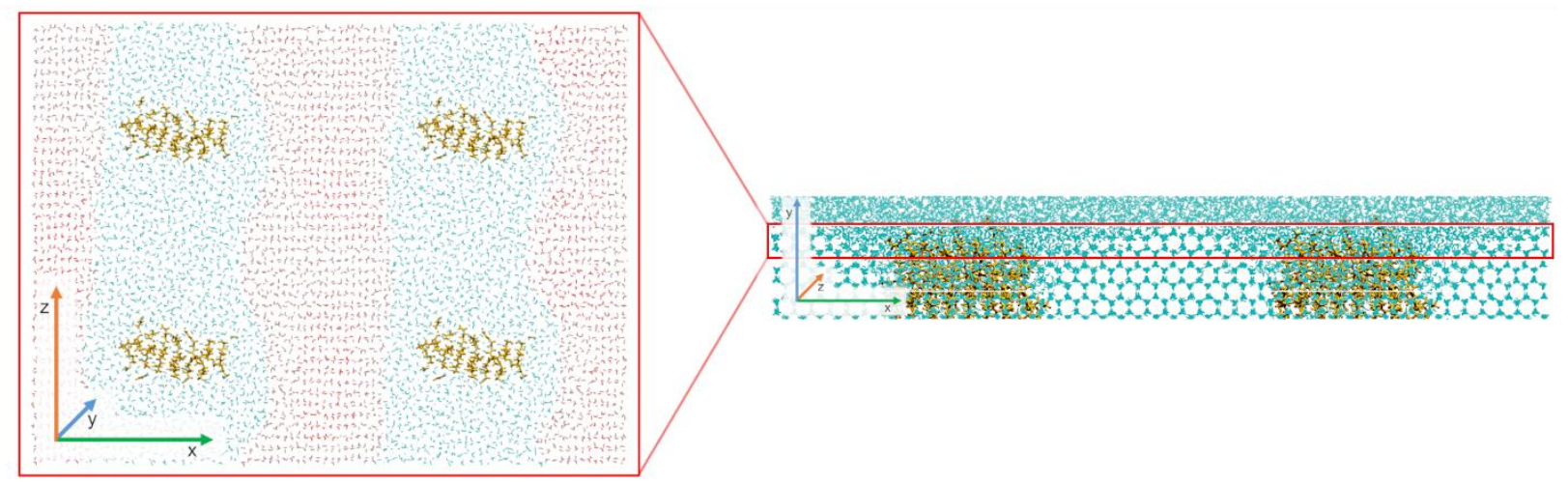

422 Figure 9. Top view of a horizontal slice to visualize the geometry of the ice surface. The water

423 molecules are roughly divided into ice (red) and water (cyan). To spatially classify the slice, the

424 front view of the box is depicted on the right.

425 To make the cylindrical shape obvious, the length axis of the cylinder is analyzed with the help

426 of slab a (Figure 5 A)). No curvature can be identified in the z-direction of slab a during all

427 simulations and at different simulation times (Figure 10).

428

$\operatorname{Sim} 1,150 \mathrm{~ns}$

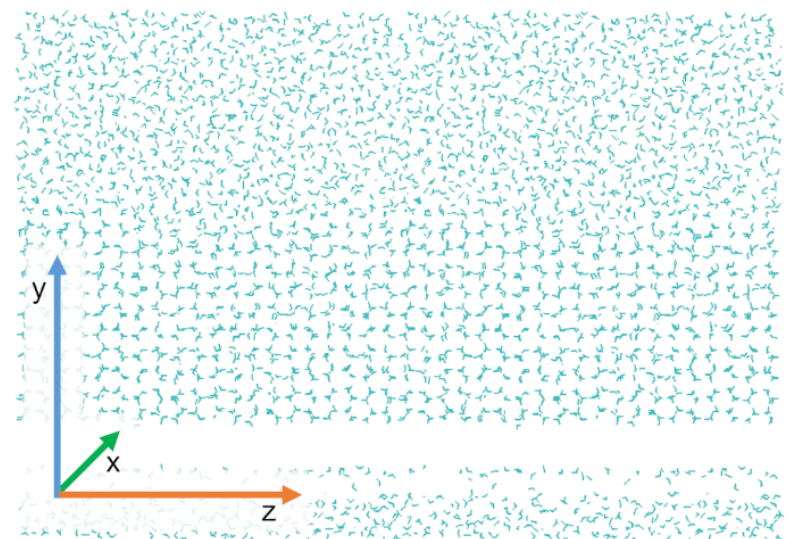

$\operatorname{Sim} 3,200 \mathrm{~ns}$

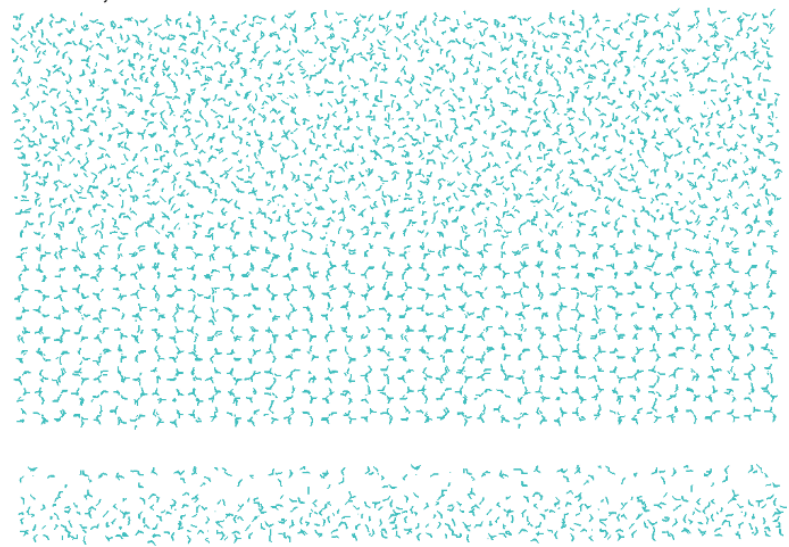

Figure 10. Slab a of two different simulations at different time points. Both slices show a straight

431 ice surface. This is also true for $\operatorname{Sim} 2$ and other times. It is worth mentioning, that no curvature is

432 formed despite the fact that the ice layer grows. 
Due to the shape of the surface, the critical radius, which determines the depression of the

434 melting temperature, has to be on the cylinder and perpendicular to the longitudinal axis ( $\mathrm{z}$ -

435 direction). In addition, it can be seen from Figure 9 that the cylinder is not exactly uniformly

436 shaped and different curvature radii are present in the x-direction. The shortest radius is directly

437 between the two AFP molecules and corresponds to slab d, whereas slab b is located at the widest

438 point of the cylinder (Figure 5 A)). Again, this is the same for all three simulations.

Now the different radii are determined and inserted into the Gibbs-Thomson equation. In this

442 way, the expected melting temperature $T_{m}(x)$ at this location is determined. In the case of the

443 critical radius, this should correspond to the temperature $T_{\min }$ already determined. The geometry

444 of the ice surface plays a critical role in the calculation of $T_{m}(x)$ with the Gibbs-Thomson equation.

445 As already shown, a cylindrical surface between the proteins with a longitudinal axis in z-direction

446 can be seen and one may assume that the critical radius is to be found on the cylinder perpendicular

447 to the longitudinal axis. We investigated this aspect in more detail for the three simulations Sim 1,

$448 \operatorname{Sim} 2$ and $\operatorname{Sim} 3$ at $T_{\min }=262.5 \mathrm{~K}$. Therefore, all reasonable radii in the system are examined,

449 not only those on the cylinder. First, the static analysis at specific time points provides information

450 about the temporal behavior of the various radii in the system. For example, radii which are

451 permanently very short can be neglected, since the resulting melting temperature $T_{m}(x)$ at this

452 point is always below the ambient temperature. Second, the radii that cannot be excluded are

453 subjected to a dynamic analysis in which they are measured at maximum curvature. 
457 At first, the slabs $\mathrm{c}$ and $\mathrm{d}$ directly between the proteins are examined (Figure 11). For slab d 458 located between the proteins in x-direction (Figure $11 \mathrm{~A})$ ), the cylindrical version of the Gibbs459 Thomson equation (Equation 4) can be used. The resulting radii of curvature (Table S1) are 460 comparably short and the melting temperature is below the ambient temperature (Table 3 ).

461

462

463

464

465

466

467

468

469

470

471

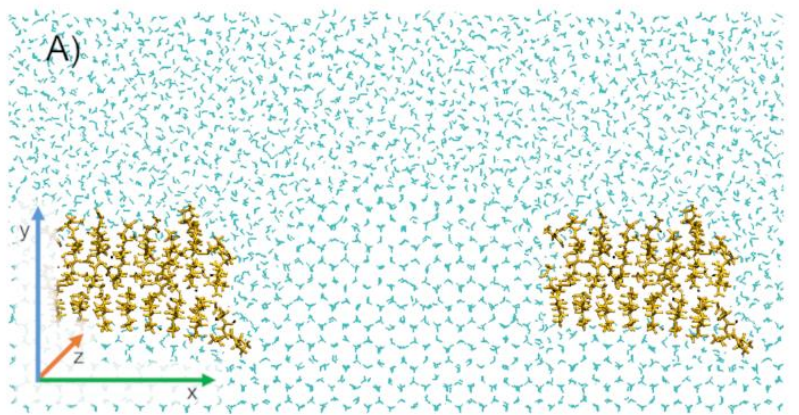
of the curvature is lower and below the height of the protein.

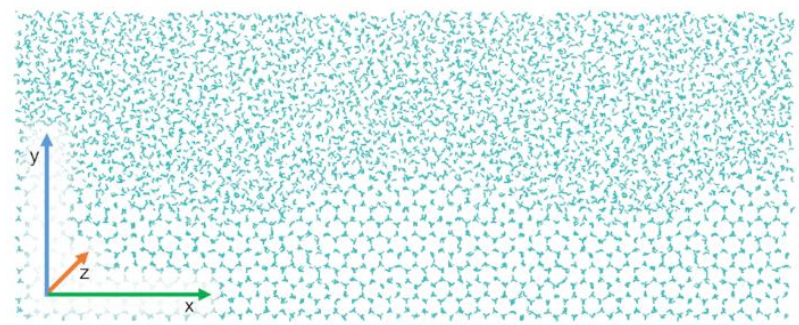

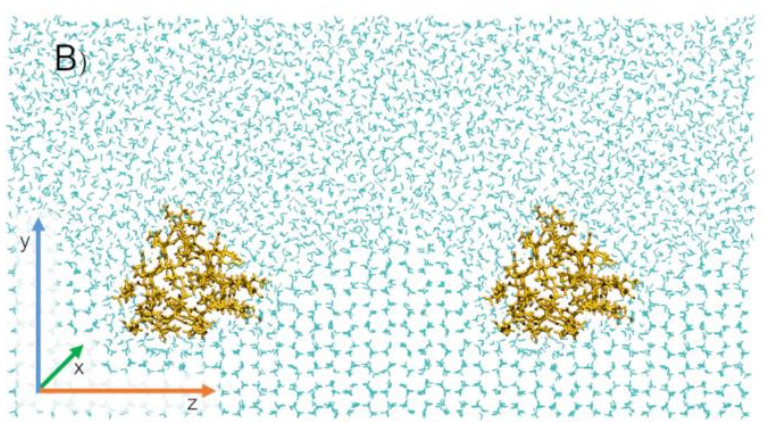

Figure 11. A) Slab d of Sim 2 at 200 ns. The ice surface between the proteins is strongly curved and the top of the ice surface is slightly above the protein. B) Slab c of Sim 1 at $175 \mathrm{~ns}$. The height

In contrast, slab c between the proteins in z-direction (Figure $11 \mathrm{~B}$ )) is not part of the cylindrical surface geometry and therefore the cylindrical geometry factor cannot be used. For the calculation of the melting temperature with Equation 5 we need the radius of curvature perpendicular to slab $\mathrm{c}$ in $\mathrm{x}$-direction. This is delivered by the surface analysis of slab b (Figure 12).

Figure 12. Slab b of Sim 3 at 200 ns. In the center the curvature has formed, which leads to negative curvatures flanking the elevation in the center. The minima of these negative curvatures 472 are between the proteins in z-direction. 
473 It turns out that a minimum height of the ice surface with a negative radius of slab $b$ is directly

474 between the proteins. For the calculation of the corresponding melting temperature, Equation 5

475 was used with the two perpendicular radii at the crossing section (c and b). As the radius in $\mathrm{x}$ -

476 direction is negative, the calculation of melting temperatures leads to comparably high melting

477 temperatures (Table 3). Due to the negative radius there is a high tendency for water molecules to

478 adsorb to the surface at this point. Nevertheless, by filling this area the radius increases to zero

479 (flat surface) and the radius in $\mathrm{z}$-direction dominates the melting temperature. Yet the radius in $\mathrm{z}$ -

480 direction is too small to be the critical radius. One can see this by elaboration of the measured radii

481 for different simulation times (Table S2). For these reasons we assume that the critical radius

482 cannot be located at this position.

483 Table 3. Melting temperatures according to the Gibbs-Thomson equation at slab c and d at 200

484 ns. Ambient temperature is $262.5 \mathrm{~K}$

\begin{tabular}{|l|l|l|l|}
\hline Simulation & Time / ns & Slab & Temperature $T_{m}(x) / \mathrm{K}$ \\
\hline 1 & 200 & $\mathrm{~d}$ & $261.47 \pm 0.36$ \\
\hline 2 & 200 & $\mathrm{~d}$ & $261.15 \pm 0.49$ \\
\hline 3 & 200 & $\mathrm{~d}$ & $262.10 \pm 0.17$ \\
\hline 1 & 200 & $\mathrm{~b}+\mathrm{c}$ & 262.63 \\
\hline 2 & 200 & $\mathrm{~b}+\mathrm{c}$ & 270.79 \\
\hline 3 & 200 & $\mathrm{~b}+\mathrm{c}$ & 266.87 \\
\hline
\end{tabular}

485

486 A similar problem arises for the diagonals, slab e and $\mathrm{f}$. They are located at the cylinder but to 487 use the cylindrical Gibbs-Thomson equation, they need to be perpendicular to the length axis of 488 the cylinder. If Equation 4 is used erroneously, the radii will be incorrectly prolonged leading to 489 an unfeasible high melting temperature as show in Table 4. On the other hand, one can state that 
490 slab e and f are approximately perpendicular and calculate the melting temperature with these two 491 radii and Equation 5. This results in comparably low values for the melting temperature (Table 5) 492 and thus provides evidence that in this system the longest distance between the proteins is not 493 decisive for the melting point depression.

494 Table 4. Melting temperature of slab e and f, calculated with the cylindrical Gibbs-Thomson 495 equation (Equation 4)

\begin{tabular}{|l|l|l|l|}
\hline Simulation & Time /ns & Slab & Temperature $T_{m}(x) / \mathrm{K}$ \\
\hline 1 & 200 & $\mathrm{e}$ & $264.64 \pm 0.16$ \\
\hline 2 & 200 & $\mathrm{e}$ & $263.42 \pm 0.31$ \\
\hline 3 & 200 & $\mathrm{e}$ & $264.58 \pm 0.19$ \\
\hline 1 & 200 & $\mathrm{f}$ & $264.22 \pm 0.24$ \\
\hline 2 & 200 & $\mathrm{f}$ & $263.70 \pm 0.09$ \\
\hline 3 & 200 & $\mathrm{f}$ & $264.37 \pm 0.13$ \\
\hline
\end{tabular}

496

497 Table 5. Corresponding melting temperatures of slab e and f, calculated with the elliptical Gibbs498 Thomson equation (Equation 5)

\begin{tabular}{|l|l|l|l|}
\hline Simulation & Time / ns & Slab & Temperature $T_{m}(x) / \mathrm{K}$ \\
\hline 1 & 200 & $\mathrm{e}+\mathrm{f}$ & 259.07 \\
\hline 2 & 200 & $\mathrm{e}+\mathrm{f}$ & 257.33 \\
\hline 3 & 200 & $\mathrm{e}+\mathrm{f}$ & 259.16 \\
\hline
\end{tabular}

500 The last slab to be analyzed is the most promising, which is slab b. It is perpendicular to the 501 longitudinal axis and at the same time the widest point of the cylinder along slab a. In addition, the 502 usage of the cylindrical Gibbs-Thomson equation is perfectly applicable in that case. 
503 As seen in Table 6 most of the calculated melting temperatures are above $T_{\min }=262.5 \mathrm{~K}$. This

504 means that the curvature would still be able to grow and the maximum melting point depression is 505 not reached yet.

506 Table 6. Resulting temperature range for the melting point at the position of slice $\mathrm{b}$ at fixed times

\begin{tabular}{|l|l|l|l|}
\hline Simulation & Time $/ \mathrm{ns}$ & Slice & Temperature $T_{m}(x) / \mathrm{K}$ \\
\hline 1 & 175 & $\mathrm{~b}$ & $262.97 \pm 0.18$ \\
\hline 1 & 200 & $\mathrm{~b}$ & $265.52 \pm 0.12$ \\
\hline 2 & 175 & $\mathrm{~b}$ & $264.18 \pm 0.17$ \\
\hline 2 & 200 & $\mathrm{~b}$ & $265.50 \pm 0.32$ \\
\hline 3 & 175 & $\mathrm{~b}$ & $265.63 \pm 0.08$ \\
\hline 3 & 200 & $\mathrm{~b}$ & $264.98 \pm 0.01$ \\
\hline
\end{tabular}

508 Only the melting temperature $T_{m}(x)$ at $175 \mathrm{~ns}$ in Sim1 seems to be in the right order of 509 magnitude. In addition, these values suggest that there are large differences between the 510 simulations. However, keeping in mind that the ice surface is in a dynamic equilibrium it is not 511 surprising that the radii of curvature are changing over time and cannot be expected to be the same 512 between different simulations at fixed times. It can be concluded from the static analysis that the 513 individual simulations show differences and therefore fixed time points cannot be directly 514 compared with each other. Although the overall ice formation seems to be similar based on the 515 density curves, the formation and variation of the curvature develops is different in each 516 simulation. The curvature may be formed the same way with a similar radius, but this is 517 coincidence for a fixed time point. Another reason for the deviations of the three simulations at $518 \quad 262.5 \mathrm{~K}$ may be the slightly different binding orientations of the AFP since this could have an 
519 impact on the ice formation and the surface topology. Therefore, a dynamic analysis of the most

520 promising surface area of slab $\mathrm{b}$ is shown in the next chapter.

$522 \quad$ Dynamic analysis

523 In the dynamic analysis, the development of slab $\mathrm{b}$ was examined throughout the simulation.

524 During the simulation time, the ice curvature at slab b builds up until a certain extent but then starts 525 to melt again (Figure 13). This happens repetitively throughout all simulations and during the 526 whole simulation time showing impressively the dynamic equilibrium. In contrast, the curvature 527 of all other slabs is formed without the curvature melting away completely and may be 528 approximated as continuously growing until the maximum curvature is reached. This does not 529 mean that the ice surface here is rigid and that there is no dynamic equilibrium between melting 530 and freezing. Nevertheless, it stands out that the ice formation and the ice surface in slab b is far 531 more dynamic than in the other slabs.

532 The ice formation at the position of slice $\mathrm{b}$ was recorded and the radius of curvature was 533 determined whenever it reaches a maximum. This should yield a melting temperature in the range 534 of the previously determined $T_{\min }$. 


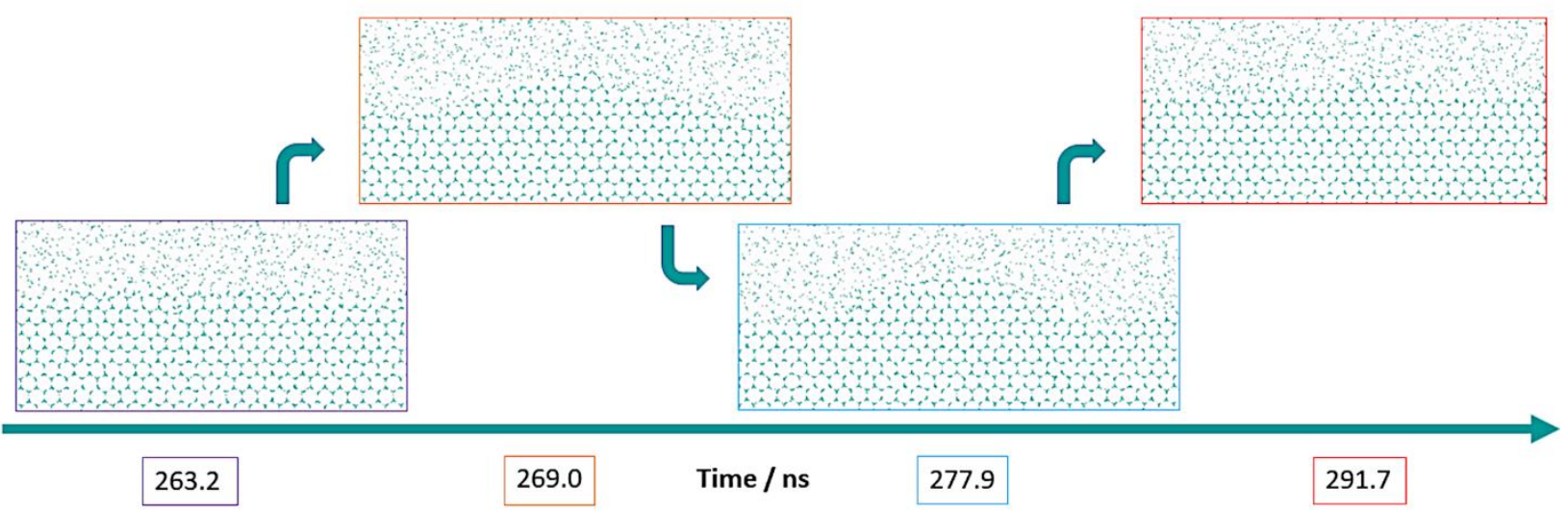

Figure 13. Formation of the curvature between 263 and $292 \mathrm{~ns}$ at slab b (yz plane) of Sim 3. At

$539263 \mathrm{~ns}$, no curvature is visible. In the further course of the simulation, the curvature starts to form

540 and is stable for around $20 \mathrm{~ns}$. During this time, minor fluctuations happen, but no significant

541 growth or melting is observed. After $30 \mathrm{~ns}$, the curvature is completely melted and the ice

542 formations starts again to form a new curvature.

543 The resulting melting temperatures $T_{m}(x)$ shown in Table 7 were calculated with the cylindrical

544 Gibbs-Thomson equation (Equation 4). They are very close to the observed $T_{\min }$ of $262.5 \mathrm{~K}$.

545 However, the values tend to be somewhat higher which would be in agreement with the previous

546 observation that Sim 1 and Sim 2 could freeze during longer simulations.

547 Table 7. Melting point at position b determined at maximum curvature

\begin{tabular}{|l|l|l|l|}
\hline Simulation & Time $/ \mathrm{ns}$ & Slice & Temperature $T_{m}(x) / \mathrm{K}$ \\
\hline 1 & 172.7 & $\mathrm{~b}$ & $263.21 \pm 0.29$ \\
\hline 2 & 122.9 & $\mathrm{~b}$ & $262.75 \pm 0.09$ \\
\hline 2 & 178.9 & $\mathrm{~b}$ & $262.46 \pm 0.22$ \\
\hline 3 & 217.2 & $\mathrm{~b}$ & $262.94 \pm 0.08$ \\
\hline
\end{tabular}


Because of these findings, we assume that the critical radius is located at the position of slab $\mathrm{b}$.

550 To summarize the results of the dynamic analysis, it can be said that the length of the radii and the

551 resulting melting temperatures at slab $b$ are in very good agreement with $T_{\min }$. It is noteworthy

552 that the critical radius is not found between the proteins and is located on the free, unoccupied ice

553 crystal surface. Contrary to Naullage et al., the critical radius in our simulation is not located at the

554 widest distance in the distribution since this would be the diagonal between the proteins. Instead,

555 one could say that the critical radius is located at the largest distance of the formed geometric

556 structure on the ice surface.

557 In addition, it is important for us to emphasize once again that the simulations reproduce the

558 Gibbs-Thomson effect well, but a comparison of the simulation with experimentally measured

559 thermal hysteresis is not possible. Reasons for this have already been given, such as the unknown

560 surface occupancy of the AFP on the ice crystal and the distribution of the distances between the

561 proteins, or the fact that the ice growth is only investigated at one specific ice crystal plane. As

562 already mentioned before, the determination of the affinity of the protein to the single crystal

563 surface is of great importance. Due to the specification of the box size, this interaction is not

564 correctly reproduced in the simulation. It is obvious by repeated simulation whether a protein binds

565 better or not, but in the case that it binds, the surface occupancy is predetermined by the box.

566 Therefore, it would be desirable to be able to determine this binding strength unambiguously.

567 Kumari et al. also proposed a new method to compare the adsorption behavior of different AFP or

568 towards different ice crystal planes. This method should be evaluated in more detail. In

569 combination with other MD simulations, this could provide further insights into the functioning of

570 AFP and molecules with similar properties. Furthermore, the current incompatibility of

571 experiments and simulations could be improved in the future. 
573 As a general result of our investigation, we can state that the geometry of ice surface is extremely

574 important and may not be guessed upfront the simulation. Due to the rectangular arrangement of

575 the protein and its images, an ellipsoidal curvature was expected but a cylindrical ice surface has

576 been observed in all simulations on the surface. For this reason, it is not purposeful to estimate a

577 maximum radius just from the distances between the proteins. We showed that the critical radius

578 is on a slab where no protein is adsorbed. By simulating different temperatures, the minimum

579 temperature at which the resulting curvature prevents ice growth was determined and is at $T_{\min }=$

$580 \quad 262.5 \mathrm{~K}$. This is in good agreement with the value calculated with the Gibbs-Thomson equation at

581 the critical radius. For the identification of the critical radius is important that the simulation time

582 is sufficient and that the dynamics auf the ice front is taken into account. We showed that in our

583 case the critical radius was the most dynamic one and not located at the longest distance between

584 the adsorbed molecules. Therefore, it is necessary to determine this radius over the course of the 585 simulation.

586 Over all, our results show on the one hand that the Gibbs-Thomson effect can be taken as the 587 basis of thermal hysteresis and that MD simulations are suitable for the prediction of the melting 588 point depression. The simulations could provide the possibility to compare different AFP or 589 mutants based on their thermal hysteresis in an identical system with same distances between the 590 proteins. The force field used could also have an influence on the adsorption of the water molecules 591 to the ice structure in the simulation. This should be evaluated in future studies. However, it is still 592 not possible to compare an experimentally determined thermal hysteresis with a value obtained by 593 simulation. 
596 Table S1. Radii and corresponding melting temperatures of the static analysis calculated with the

597 cylindrical Gibbs-Thomson equation

\begin{tabular}{|l|l|l|l|l|}
\hline Simulation & Slab & Time / ns & Radius / nm & Temperature $T_{m}(x) / \mathrm{K}$ \\
\hline 1 & b & 150 & 7.63 & 265.69 \\
\hline 1 & b & 150 & 7.29 & 265.50 \\
\hline 1 & b & 150 & 7.40 & 265.56 \\
\hline 1 & b & 175 & 4.51 & 262.84 \\
\hline 1 & b & 175 & 4.54 & 262.89 \\
\hline 1 & b & 175 & 4.73 & 263.17 \\
\hline 1 & b & 200 & 7.10 & 265.38 \\
\hline 1 & b & 200 & 7.45 & 265.59 \\
\hline 1 & b & 200 & 7.44 & 265.58 \\
\hline 1 & c & 150 & 3.75 & 261.43 \\
\hline 1 & c & 150 & 3.62 & 261.12 \\
\hline 1 & c & 150 & 3.80 & 261.55 \\
\hline 1 & c & 175 & 3.24 & 260.12 \\
\hline 1 & c & 175 & 3.19 & 259.97 \\
\hline 1 & c & 175 & 3.35 & 260.44 \\
\hline 1 & c & 200 & 2.62 & 257.80 \\
\hline 1 & c & 200 & 2.68 & 258.08 \\
\hline 1 & c & 200 & 2.63 & 257.86 \\
\hline 1 & d & 150 & 3.65 & 261.19 \\
\hline 1 & d & 150 & 3.76 & 261.45 \\
\hline & & 3.60 & 261.09 \\
\hline 1 & & & & \\
\hline 1 & & & & \\
\hline & & & & \\
\hline
\end{tabular}




\begin{tabular}{|c|c|c|c|c|}
\hline 1 & $\mathrm{~d}$ & \begin{tabular}{|l|}
175 \\
\end{tabular} & 3.14 & 259.79 \\
\hline 1 & $d$ & 175 & 3.08 & 259.61 \\
\hline 1 & $d$ & 175 & 3.25 & 260.13 \\
\hline 1 & $\mathrm{~d}$ & 200 & 3.64 & 261.18 \\
\hline 1 & $d$ & 200 & 3.96 & 261.87 \\
\hline 1 & $\mathrm{~d}$ & 200 & 3.72 & 261.36 \\
\hline 1 & $\mathrm{e}$ & 150 & 6.87 & 265.23 \\
\hline 1 & $\mathrm{e}$ & 150 & 6.84 & 265.22 \\
\hline 1 & $\mathrm{e}$ & 150 & 6.97 & 265.30 \\
\hline 1 & e & 175 & 5.53 & 264.12 \\
\hline 1 & $\mathrm{e}$ & 175 & 5.54 & 264.14 \\
\hline 1 & $\mathrm{e}$ & 175 & 5.40 & 263.99 \\
\hline 1 & $\mathrm{e}$ & 200 & 5.94 & 264.51 \\
\hline 1 & $\mathrm{e}$ & 200 & 6.03 & 264.60 \\
\hline 1 & $\mathrm{e}$ & 200 & 6.31 & 264.82 \\
\hline 1 & $\mathrm{f}$ & 150 & 6.18 & 264.72 \\
\hline 1 & $f$ & 150 & 5.99 & 264.56 \\
\hline 1 & $f$ & 150 & 6.11 & 264.67 \\
\hline 1 & $f$ & 175 & 4.89 & 263.38 \\
\hline 1 & $f$ & 175 & 5.20 & 263.76 \\
\hline 1 & $\mathrm{f}$ & 175 & 5.08 & 263.62 \\
\hline 1 & $f$ & 200 & 5.51 & 264.10 \\
\hline 1 & $f$ & 200 & 5.47 & 264.06 \\
\hline 1 & $\mathrm{f}$ & 200 & 5.91 & 264.49 \\
\hline 2 & $\mathrm{~b}$ & 150 & 6.87 & 265.23 \\
\hline 2 & $\mathrm{~b}$ & 150 & 7.12 & 265.39 \\
\hline
\end{tabular}




\begin{tabular}{|c|c|c|c|c|}
\hline 2 & $\mathrm{~b}$ & \begin{tabular}{|l|}
150 \\
\end{tabular} & 7.26 & 265.48 \\
\hline 2 & $\mathrm{~b}$ & 175 & 5.78 & 264.37 \\
\hline 2 & $\mathrm{~b}$ & 175 & 5.47 & 264.06 \\
\hline 2 & $\mathrm{~b}$ & 175 & 5.53 & 264.12 \\
\hline 2 & $\mathrm{~b}$ & 200 & 6.74 & 265.14 \\
\hline 2 & $\mathrm{~b}$ & 200 & 7.52 & 265.63 \\
\hline 2 & $\mathrm{~b}$ & 200 & 7.73 & 265.74 \\
\hline 2 & $\mathrm{c}$ & 150 & 2.99 & 259.29 \\
\hline 2 & $\mathrm{c}$ & 150 & 3.12 & 259.73 \\
\hline 2 & $\mathrm{c}$ & 150 & 3.24 & 260.11 \\
\hline 2 & $\mathrm{c}$ & 175 & 3.18 & 259.95 \\
\hline 2 & $\mathrm{c}$ & 175 & 3.35 & 260.43 \\
\hline 2 & $\mathrm{c}$ & 175 & 3.42 & 260.61 \\
\hline 2 & $\mathrm{c}$ & 200 & 3.72 & 261.36 \\
\hline 2 & $\mathrm{c}$ & 200 & 3.74 & 261.40 \\
\hline 2 & $\mathrm{c}$ & 200 & 3.89 & 261.74 \\
\hline 2 & $\mathrm{~d}$ & 150 & 2.63 & 257.85 \\
\hline 2 & $\mathrm{~d}$ & 150 & 2.63 & 257.86 \\
\hline 2 & $\mathrm{~d}$ & 150 & 2.66 & 258.00 \\
\hline 2 & $\mathrm{~d}$ & 175 & 4.24 & 262.39 \\
\hline 2 & $\mathrm{~d}$ & 175 & 4.36 & 262.60 \\
\hline 2 & $d$ & 175 & 4.48 & 262.80 \\
\hline 2 & $\mathrm{~d}$ & 200 & 3.49 & 260.80 \\
\hline 2 & $\mathrm{~d}$ & 200 & 3.54 & 260.93 \\
\hline 2 & $\mathrm{~d}$ & 200 & 3.88 & 261.71 \\
\hline 2 & e & 150 & 4.53 & 262.87 \\
\hline
\end{tabular}




\begin{tabular}{|c|c|c|c|c|}
\hline 2 & $\mathrm{e}$ & 150 & 4.59 & 262.96 \\
\hline 2 & $\mathrm{e}$ & 150 & 4.52 & 262.86 \\
\hline 2 & e & 175 & 4.56 & 262.91 \\
\hline 2 & $\mathrm{e}$ & 175 & 4.55 & 262.91 \\
\hline 2 & $\mathrm{e}$ & 175 & 4.59 & 262.96 \\
\hline 2 & e & 200 & 4.71 & 263.13 \\
\hline 2 & $\mathrm{e}$ & 200 & 4.89 & 263.38 \\
\hline 2 & $\mathrm{e}$ & 200 & 5.19 & 263.75 \\
\hline 2 & $f$ & 150 & 5.02 & 263.55 \\
\hline 2 & $\mathrm{f}$ & 150 & 4.86 & 263.35 \\
\hline 2 & $\mathrm{f}$ & 150 & 5.01 & 263.54 \\
\hline 2 & $\mathrm{f}$ & 175 & 6.12 & 264.67 \\
\hline 2 & $\mathrm{f}$ & 175 & 6.48 & 264.96 \\
\hline 2 & $\mathrm{f}$ & 175 & 5.91 & 264.49 \\
\hline 2 & $f$ & 200 & 5.06 & 263.59 \\
\hline 2 & $\mathrm{f}$ & 200 & 5.21 & 263.78 \\
\hline 2 & $f$ & 200 & 5.16 & 263.71 \\
\hline 3 & $\mathrm{~b}$ & 150 & 6.05 & 264.61 \\
\hline 3 & $\mathrm{~b}$ & 150 & 6.23 & 264.76 \\
\hline 3 & $\mathrm{~b}$ & 150 & 6.37 & 264.88 \\
\hline 3 & $\mathrm{~b}$ & 175 & 7.42 & 265.57 \\
\hline 3 & $\mathrm{~b}$ & 175 & 7.49 & 265.61 \\
\hline 3 & $\mathrm{~b}$ & 175 & 7.69 & 265.72 \\
\hline 3 & $\mathrm{~b}$ & 200 & 6.52 & 264.98 \\
\hline 3 & $\mathrm{~b}$ & 200 & 6.52 & 264.99 \\
\hline 3 & $\mathrm{~b}$ & 200 & 6.50 & 264.97 \\
\hline
\end{tabular}




\begin{tabular}{|c|c|c|c|c|}
\hline 3 & $\mathrm{c}$ & 150 & 3.28 & 260.22 \\
\hline 3 & $\mathrm{c}$ & 150 & 3.71 & 261.34 \\
\hline 3 & $\mathrm{c}$ & 150 & 3.57 & 261.00 \\
\hline 3 & $\mathrm{c}$ & 175 & 2.79 & 258.57 \\
\hline 3 & $\mathrm{c}$ & 175 & 2.95 & 259.16 \\
\hline 3 & $\mathrm{c}$ & 175 & 2.86 & 258.83 \\
\hline 3 & $\mathrm{c}$ & 200 & 3.15 & 259.83 \\
\hline 3 & $\mathrm{c}$ & 200 & 3.39 & 260.54 \\
\hline 3 & $\mathrm{c}$ & 200 & 3.14 & 259.82 \\
\hline 3 & d & 150 & 3.15 & 259.84 \\
\hline 3 & $d$ & 150 & 3.27 & 260.21 \\
\hline 3 & $\mathrm{~d}$ & 150 & 3.45 & 260.70 \\
\hline 3 & d & 175 & 3.19 & 259.96 \\
\hline 3 & $\mathrm{~d}$ & 175 & 3.31 & 260.31 \\
\hline 3 & $\mathrm{~d}$ & 175 & 3.40 & 260.56 \\
\hline 3 & $\mathrm{~d}$ & 200 & 4.01 & 261.98 \\
\hline 3 & $d$ & 200 & 4.04 & 262.04 \\
\hline 3 & $\mathrm{~d}$ & 200 & 4.18 & 262.29 \\
\hline 3 & $\mathrm{e}$ & 150 & 6.43 & 264.92 \\
\hline 3 & $\mathrm{e}$ & 150 & 6.40 & 264.89 \\
\hline 3 & e & 150 & 6.48 & 264.95 \\
\hline 3 & e & 175 & 5.85 & 264.43 \\
\hline 3 & e & 175 & 6.08 & 264.63 \\
\hline 3 & e & 175 & 5.90 & 264.48 \\
\hline 3 & $\mathrm{e}$ & 200 & 5.82 & 264.40 \\
\hline 3 & $\mathrm{e}$ & 200 & 6.00 & 264.57 \\
\hline
\end{tabular}




\begin{tabular}{|l|l|l|l|l|}
\hline 3 & e & 200 & 6.25 & 264.78 \\
\hline 3 & f & 150 & 5.71 & 264.31 \\
\hline 3 & f & 150 & 5.75 & 264.34 \\
\hline 3 & f & 150 & 5.72 & 264.31 \\
\hline 3 & f & 175 & 5.89 & 264.47 \\
\hline 3 & f & 175 & 6.16 & 264.70 \\
\hline 3 & f & 175 & 6.32 & 264.84 \\
\hline 3 & f & 200 & 5.71 & 264.31 \\
\hline 3 & f & 200 & 5.94 & 264.52 \\
\hline 3 & f & 200 & 5.69 & 264.28 \\
\hline
\end{tabular}

599 Table S2. Radii and melting temperatures when slab c and b are combined. For the calculation,

600 the elliptical Gibbs-Thomson equation is used.

\begin{tabular}{|l|l|l|l|l|}
\hline Simulation & Time / ns & $\begin{array}{l}\text { Average radius } \\
\text { for slab } \mathrm{b} / \mathrm{nm}\end{array}$ & $\begin{array}{l}\text { Average radius } \\
\text { for slab c } / \mathrm{nm}\end{array}$ & $\begin{array}{l}\text { Temperature } \\
T_{m}(x) / \mathrm{K}\end{array}$ \\
\hline 1 & 150 & -3.09 & 3.72 & 271.51 \\
\hline 1 & 175 & -4.05 & 3.26 & 267.94 \\
\hline 1 & 200 & -6.65 & 2.64 & 262.63 \\
\hline 2 & 150 & -4.70 & 3.11 & 266.40 \\
\hline 2 & 175 & -4.68 & 3.32 & 267.05 \\
\hline 2 & 200 & -3.38 & 3.78 & 270.79 \\
\hline 3 & 150 & -4.67 & 3.52 & 267.59 \\
\hline 3 & 175 & -4.65 & 2.87 & 265.61 \\
\hline 3 & 200 & -4.61 & 3.23 & 266.87 \\
\hline
\end{tabular}

601

602 
603 Table S3. Radii and melting temperatures when slab e and $f$ are combined. For the calculation, the 604 elliptical Gibbs-Thomson equation is used.

\begin{tabular}{|l|l|l|l|l|}
\hline Simulation & Time / ns & $\begin{array}{l}\text { Average radius } \\
\text { for slab e } / \mathrm{nm}\end{array}$ & $\begin{array}{l}\text { Average radius } \\
\text { for slab f } / \mathrm{nm}\end{array}$ & $\begin{array}{l}\text { Temperature } \\
T_{m}(x) / \mathrm{K}\end{array}$ \\
\hline 1 & 150 & 6.89 & 6.09 & 260.10 \\
\hline 1 & 175 & 5.49 & 5.06 & 257.88 \\
\hline 1 & 200 & 6.09 & 5.63 & 259.07 \\
\hline 2 & 150 & 4.55 & 4.96 & 256.58 \\
\hline 2 & 175 & 4.57 & 6.17 & 257.84 \\
\hline 2 & 200 & 4.93 & 5.14 & 257.33 \\
\hline 3 & 150 & 6.43 & 5.73 & 259.44 \\
\hline 3 & 175 & 5.94 & 6.12 & 259.39 \\
\hline 3 & 200 & 6.02 & 5.78 & 259.16 \\
\hline
\end{tabular}

605

606 Table S4. Radii and corresponding melting temperatures at the position of slab $b$ during the

607 dynamic analysis. The melting temperatures are calculated with the cylindrical version of the 608 Gibbs-Thomson equation

\begin{tabular}{|l|l|l|l|l|}
\hline Simulation & Slab & Time /ns & Radius / nm & Temperature $T_{m}(x) / \mathrm{K}$ \\
\hline 1 & $\mathrm{~b}$ & 93 & 4.86 & 263.34 \\
\hline 1 & $\mathrm{~b}$ & 93 & 4.65 & 263.05 \\
\hline 1 & $\mathrm{~b}$ & 93 & 4.79 & 263.25 \\
\hline 1 & b & 117.1 & 6.00 & 264.57 \\
\hline 1 & b & 117.1 & 5.68 & 264.28 \\
\hline 1 & b & 117.1 & 5.69 & 264.28 \\
\hline 1 & b & 172.7 & 4.82 & 263.29 \\
\hline
\end{tabular}




\begin{tabular}{|c|c|c|c|c|}
\hline 1 & $\mathrm{~b}$ & \begin{tabular}{|l|}
172.7 \\
\end{tabular} & 4.54 & 262.89 \\
\hline 1 & $\mathrm{~b}$ & 172.7 & 4.93 & 263.44 \\
\hline 1 & $\mathrm{~b}$ & 218.6 & 5.08 & 263.62 \\
\hline 1 & $\mathrm{~b}$ & 218.6 & 5.17 & 263.73 \\
\hline 1 & $\mathrm{~b}$ & 218.6 & 5.05 & 263.59 \\
\hline 1 & $\mathrm{~b}$ & 262.1 & 6.73 & 265.13 \\
\hline 1 & $\mathrm{~b}$ & 262.1 & 7.19 & 265.44 \\
\hline 1 & $\mathrm{~b}$ & 262.1 & 6.93 & 265.27 \\
\hline 2 & $\mathrm{~b}$ & 91.9 & 7.42 & 265.57 \\
\hline 2 & $\mathrm{~b}$ & 91.9 & 7.32 & 265.51 \\
\hline 2 & $\mathrm{~b}$ & 91.9 & 7.12 & 265.39 \\
\hline 2 & $\mathrm{~b}$ & 93.7 & 5.19 & \begin{tabular}{|l}
263.76 \\
\end{tabular} \\
\hline 2 & $\mathrm{~b}$ & 93.7 & 4.99 & 263.51 \\
\hline 2 & $\mathrm{~b}$ & 93.7 & 4.96 & 263.48 \\
\hline 2 & $\mathrm{~b}$ & 111.6 & 6.94 & 265.28 \\
\hline 2 & $\mathrm{~b}$ & 111.6 & 6.83 & 265.21 \\
\hline 2 & $\mathrm{~b}$ & 111.6 & 6.84 & 265.21 \\
\hline 2 & $\mathrm{~b}$ & 122.9 & 4.47 & 262.78 \\
\hline 2 & $\mathrm{~b}$ & 122.9 & 4.39 & 262.65 \\
\hline 2 & $\mathrm{~b}$ & 122.9 & 4.49 & 262.82 \\
\hline 2 & $\mathrm{~b}$ & 178.9 & 4.42 & 262.71 \\
\hline 2 & $\mathrm{~b}$ & 178.9 & 4.16 & 262.26 \\
\hline 2 & $\mathrm{~b}$ & 178.9 & 4.25 & 262.42 \\
\hline 2 & $\mathrm{~b}$ & 238.2 & 5.60 & 264.19 \\
\hline 2 & $\mathrm{~b}$ & 238.2 & 5.54 & \begin{tabular}{|l}
264.13 \\
\end{tabular} \\
\hline 2 & $\mathrm{~b}$ & 238.2 & 5.65 & 264.25 \\
\hline
\end{tabular}




\begin{tabular}{|c|c|c|c|c|}
\hline 2 & $\mathrm{~b}$ & 263.9 & 6.17 & 264.71 \\
\hline 2 & $\mathrm{~b}$ & 263.9 & 5.89 & 264.47 \\
\hline 2 & $\mathrm{~b}$ & 263.9 & 6.11 & 264.66 \\
\hline 3 & $\mathrm{~b}$ & 81.8 & 4.11 & 262.17 \\
\hline 3 & $\mathrm{~b}$ & 81.8 & 4.14 & 262.23 \\
\hline 3 & $\mathrm{~b}$ & 81.8 & 4.13 & 262.21 \\
\hline 3 & $\mathrm{~b}$ & 96.4 & 5.76 & 264.36 \\
\hline 3 & $\mathrm{~b}$ & 96.4 & 5.55 & 264.14 \\
\hline 3 & $\mathrm{~b}$ & 96.4 & 5.82 & 264.40 \\
\hline 3 & $\mathrm{~b}$ & 131.0 & 4.92 & 263.42 \\
\hline 3 & $\mathrm{~b}$ & 131.0 & 5.03 & 263.56 \\
\hline 3 & $\mathrm{~b}$ & 131.0 & 4.91 & 263.41 \\
\hline 3 & $\mathrm{~b}$ & 191.1 & 5.21 & 263.78 \\
\hline 3 & $\mathrm{~b}$ & 191.1 & 5.50 & 264.09 \\
\hline 3 & $\mathrm{~b}$ & 191.1 & 5.03 & 263.55 \\
\hline 3 & $\mathrm{~b}$ & 217.2 & 4.52 & 262.86 \\
\hline 3 & $\mathrm{~b}$ & 217.2 & 4.58 & 262.94 \\
\hline 3 & $\mathrm{~b}$ & 217.2 & 4.64 & 263.03 \\
\hline 3 & $\mathrm{~b}$ & 236.2 & 6.12 & 264.67 \\
\hline 3 & $\mathrm{~b}$ & 236.2 & 6.24 & 264.77 \\
\hline 3 & $\mathrm{~b}$ & 236.2 & 6.57 & 265.02 \\
\hline 3 & $\mathrm{~b}$ & 348.8 & 4.96 & 263.47 \\
\hline 3 & $\mathrm{~b}$ & 348.8 & 4.77 & 263.22 \\
\hline 3 & $\mathrm{~b}$ & 348.8 & 4.73 & 263.16 \\
\hline 3 & $\mathrm{~b}$ & 365.7 & 5.56 & 264.15 \\
\hline 3 & $\mathrm{~b}$ & 365.7 & 5.51 & 264.10 \\
\hline
\end{tabular}




\begin{tabular}{|l|l|l|l|l|}
\hline 3 & b & 365.7 & 5.53 & 264.13 \\
\hline 3 & b & 382.5 & 5.97 & 264.54 \\
\hline 3 & b & 382.5 & 5.92 & 264.50 \\
\hline 3 & b & 382.5 & 6.12 & 264.67 \\
\hline 3 & b & 401.7 & 6.87 & 265.23 \\
\hline 3 & b & 401.7 & 6.51 & 264.98 \\
\hline 3 & b & 401.7 & 6.70 & 265.12 \\
\hline
\end{tabular}

609

610 
612 (1) Davies, P. L. Ice-binding proteins: a remarkable diversity of structures for stopping and 613 starting ice growth. Trends in biochemical sciences 2014, 39, 548-555.

614 (2) Duman, J. G. Antifreeze and ice nucleator proteins in terrestrial arthropods. Annual review 615 of physiology 2001, 63, 327-357.

616 (3) Bredow, M.; Walker, V. K. Ice-Binding Proteins in Plants. Frontiers in plant science 2017, $6178,2153$.

618 (4) Muñoz, P. A.; Márquez, S. L.; González-Nilo, F. D.; Márquez-Miranda, V.; Blamey, J. M. 619 Structure and application of antifreeze proteins from Antarctic bacteria. Microbial cell factories $620 \quad 2017,16,138$.

621 (5) Muldrew, K.; McGann, L. E. Mechanisms of intracellular ice formation. Biophysical journal $6221990,57,525-532$.

623 (6) Białkowska, A.; Majewska, E.; Olczak, A.; Twarda-Clapa, A. Ice Binding Proteins: Diverse 624 Biological Roles and Applications in Different Types of Industry. Biomolecules 2020, 10.

625 (7) DeVries, A. L. Glycoproteins as Biological Antifreeze Agents in Antarctic Fishes. Science $626 \mathbf{1 9 7 1}, 1152-1155$.

627 (8) Raymond, J. A.; DeVries, A. L. Adsorption inhibition as a mechanism of freezing resistance 628 in polar fishes. Proceedings of the National Academy of Sciences of the United States of America $629 \quad \mathbf{1 9 7 7}, 74$, 2589-2593. 
(9) Celik, Y.; Graham, L. A.; Mok, Y.-F.; Bar, M.; Davies, P. L.; Braslavsky, I. Superheating of

631 ice crystals in antifreeze protein solutions. Proceedings of the National Academy of Sciences of 632 the United States of America 2010, 107, 5423-5428.

633 (10) Hanada, Y.; Nishimiya, Y.; Miura, A.; Tsuda, S.; Kondo, H. Hyperactive antifreeze protein 634 from an Antarctic sea ice bacterium Colwellia sp. has a compound ice-binding site without 635 repetitive sequences. The FEBS journal 2014, 281, 3576-3590.

636 (11) Scotter, A. J.; Marshall, C. B.; Graham, L. A.; Gilbert, J. A.; Garnham, C. P.; Davies, P. L. 637 The basis for hyperactivity of antifreeze proteins. Cryobiology 2006, 53, 229-239.

638 (12) Bar Dolev, M.; Braslavsky, I.; Davies, P. L. Ice-Binding Proteins and Their Function. 639 Annual review of biochemistry 2016, 85, 515-542.

640 (13) Olijve, L. L. C.; Meister, K.; DeVries, A. L.; Duman, J. G.; Guo, S.; Bakker, H. J.; Voets, 641 I. K. Blocking rapid ice crystal growth through nonbasal plane adsorption of antifreeze proteins. 642 Proceedings of the National Academy of Sciences of the United States of America 2016, 113, $643 \quad 3740-3745$.

644 (14) Davies PL, H. C. L. Biochemistry of fish antifreeze proteins. FASEB J. 1990, 2460-2468.

645 (15) Martino, M. N.; Zaritzky, N. E. Ice recrystallization in a model system and in frozen muscle 646 tissue. Cryobiology 1989, 26, 138-148.

647 (16) Bevilacqua, A. E.; Zaritzky, N. E. Ice Recrystallization in Frozen Beef. J Food Science $648 \quad \mathbf{1 9 8 2}, 47,1410-1414$.

649 (17) Knight CA, DeVries AL, Oolman LD. Fish antifreeze protein and the freezing and 650 recrystallization of ice. Nature $1984,15-21$. 
(18) Gaukel, V.; Leiter, A.; Spieß, W. E.L. Synergism of different fish antifreeze proteins and 652 hydrocolloids on recrystallization inhibition of ice in sucrose solutions. Journal of Food 653 Engineering 2014, 141, 44-50.

654 (19) Knight C. A., DeVries A. L. Melting Inhibition and Superheating of ice by an AFGP. 655 Science 1989, 505-507.

656 (20) Jackson, C. L.; McKenna, G. B. The melting behavior of organic materials confined in 657 porous solids. The Journal of chemical physics 1990, 93, 9002-9011.

658 (21) Basu, K.; Garnham, C. P.; Nishimiya, Y.; Tsuda, S.; Braslavsky, I.; Davies, P. Determining 659 the ice-binding planes of antifreeze proteins by fluorescence-based ice plane affinity. Journal of 660 visualized experiments : JoVE 2014, e51185.

661 (22) Pertaya, N.; Marshall, C. B.; Celik, Y.; Davies, P. L.; Braslavsky, I. Direct visualization of 662 spruce budworm antifreeze protein interacting with ice crystals: basal plane affinity confers 663 hyperactivity. Biophysical journal 2008, 95, 333-341.

664 (23) Ramløv, H.; DeVries, A. L.; Wilson, P. W. Antifreeze glycoproteins from the antarctic fish 665 Dissostichus mawsoni studied by differential scanning calorimetry (DSC) in combination with 666 nanolitre osmometry. Cryo letters 2005, 26, 73-84.

667 (24) Gaede-Koehler, A.; Kreider, A.; Canfield, P.; Kleemeier, M.; Grunwald, I. Direct 668 measurement of the thermal hysteresis of antifreeze proteins (AFPs) using sonocrystallization. 669 Analytical chemistry 2012, 84, 10229-10235.

670 (25) Hassa-Roudsari, M.; Goff, H. D. A new quantitative method to measure activity of ice 671 structuring proteins using differential scanning calorimetry. Cryo letters 2012, 33, 118-125. 
672 (26) Drori, R.; Davies, P. L.; Braslavsky, I. Experimental correlation between thermal hysteresis 673 activity and the distance between antifreeze proteins on an ice surface. RSC Adv. 2015, 5, 78486747853.

675 (27) Weng, L.; Stott, S. L.; Toner, M. Molecular Dynamics at the Interface between Ice and 676 Poly(vinyl alcohol) and Ice Recrystallization Inhibition. Langmuir : the ACS journal of surfaces 677 and colloids $\mathbf{2 0 1 8}, 34,5116-5123$.

678 (28) Kuiper, M. J.; Morton, C. J.; Abraham, S. E.; Gray-Weale, A. The biological function of an 679 insect antifreeze protein simulated by molecular dynamics. eLife 2015, 4.

680 (29) Nada, H.; Furukawa, Y. Antifreeze proteins: computer simulation studies on the mechanism 681 of ice growth inhibition. Polym J 2012, 44, 690-698.

682 (30) Naullage, P. M.; Qiu, Y.; Molinero, V. What Controls the Limit of Supercooling and 683 Superheating of Pinned Ice Surfaces? The journal of physical chemistry letters 2018, 9, 1712 6841720.

685 (31) Midya, U. S.; Bandyopadhyay, S. Operation of Kelvin Effect in the Activities of an 686 Antifreeze Protein: A Molecular Dynamics Simulation Study. The journal of physical chemistry. 687 B 2018, 122, 3079-3087.

688 (32) Nada, H.; Furukawa, Y. Growth inhibition at the ice prismatic plane induced by a spruce 689 budworm antifreeze protein: a molecular dynamics simulation study. Physical chemistry chemical 690 physics : PCCP 2011, 13, 19936-19942. 
(33) Berendsen, H.J.C.; van der Spoel, D.; van Drunen, R. GROMACS: A message-passing 692 parallel molecular dynamics implementation. Computer Physics Communications 1995, 91, $43-$ 69356.

694 (34) Humphrey, W.; Dalke, A.; Schulten, K. VMD: Visual molecular dynamics. Journal of 695 Molecular Graphics 1996, 14, 33-38.

(35) Abascal, J. L. F.; Sanz, E.; García Fernández, R.; Vega, C. A potential model for the study 697 of ices and amorphous water: TIP4P/Ice. The Journal of chemical physics 2005, 122, 234511. 700 of the American Chemical Society 1996, 118, 11225-11236. water TIP4P/2005 and water TIP4P/Ice models by the direct coexistence technique. The Journal 703 of chemical physics 2017, 147, 244506.

(38) García Fernández, R.; Abascal, J. L. F.; Vega, C. The melting point of ice Ih for common water models calculated from direct coexistence of the solid-liquid interface. The Journal of 706 chemical physics 2006, 124, 144506.

(39) Hess, B.; Bekker, H.; Berendsen, H.J.C.; Fraaije, G.E.M. LINCS: A linear constraint solver 708 for molecular simulations. Journal of Computational Chemistry 1997, 1463-1472.

709 (40) Chakraborty, S.; Jana, B. Molecular Insight into the Adsorption of Spruce Budworm 710 Antifreeze Protein to an Ice Surface: A Clathrate-Mediated Recognition Mechanism. Langmuir : 711 the ACS journal of surfaces and colloids 2017, 33, 7202-7214. 
712 (41) Espinosa, J. R.; Vega, C.; Sanz, E. Ice-Water Interfacial Free Energy for the TIP4P, 713 TIP4P/2005, TIP4P/Ice, and mW Models As Obtained from the Mold Integration Technique. J.

714 Phys. Chem. C 2016, 120, 8068-8075.

715 (42) Kumari, S.; Muthachikavil, A. V.; Tiwari, J. K.; Punnathanam, S. N. Computational Study 716 of Differences between Antifreeze Activity of Type-III Antifreeze Protein from Ocean Pout and

717 Its Mutant. Langmuir : the ACS journal of surfaces and colloids 2020, 36, 2439-2448. 


\section{AUTHOR INFORMATION}

720 Corresponding Author

721 Julian Gerhäuser, julian.gerhaeuser@kit.edu, Kaiserstraße 12, 76131 Karlsruhe

722

\section{Author Contributions}

724 The manuscript was written through contributions of all authors. All authors have given approval

725 to the final version of the manuscript.

\section{ABBREVIATIONS}

727 AFP, antifreeze protein; IBP, ice-binding protein; M, molecular mass; MD, molecular dynamics;

728 PBC, periodic boundary condition; r, radius; sbw, spruce budworm; TH, thermal hysteresis;

729 TmAFP, tenebrio molitor antifreeze protein; VMD, Visual Molecular Dynamics; $\mathrm{x}$, diameter 